\title{
The Design and Commissioning of a Micro-cogeneration Testing Facility
}

\author{
by \\ Evan Boucher, B.Eng. \\ A thesis submitted to the \\ Faculty of Graduate and Postdoctoral Affairs \\ in partial fulfillment of the requirements for the degree of
}

\section{Master of Applied Science}

Ottawa-Carleton Institute for Mechanical and Aerospace Engineering

Department of Mechanical and Aerospace Engineering

Carleton University

Ottawa, Ontario

April, 2013

(C)Copyright

Evan Boucher, 2013 
Library and Archives

Canada

Published Heritage

Branch

395 Wellington Street

Ottawa ON K1A ON4

Canada
Bibliothèque et

Archives Canada

Direction du

Patrimoine de l'édition

395 , rue Wellington

Ottawa ON K1A ON4

Canada
Your file Votre référence

ISBN: 978-0-494-94656-5

Our file Notre référence

ISBN: 978-0-494-94656-5
NOTICE:

The author has granted a nonexclusive license allowing Library and Archives Canada to reproduce, publish, archive, preserve, conserve, communicate to the public by telecommunication or on the Internet, loan, distrbute and sell theses worldwide, for commercial or noncommercial purposes, in microform, paper, electronic and/or any other formats.

The author retains copyright ownership and moral rights in this thesis. Neither the thesis nor substantial extracts from it may be printed or otherwise reproduced without the author's permission.
AVIS:

L'auteur a accordé une licence non exclusive permettant à la Bibliothèque et Archives Canada de reproduire, publier, archiver, sauvegarder, conserver, transmettre au public par télécommunication ou par l'Internet, prêter, distribuer et vendre des thèses partout dans le monde, à des fins commerciales ou autres, sur support microforme, papier, électronique et/ou autres formats.

L'auteur conserve la propriété du droit d'auteur et des droits moraux qui protege cette thèse. $\mathrm{Ni}$ la thèse ni des extraits substantiels de celle-ci ne doivent être imprimés ou autrement reproduits sans son autorisation.
In compliance with the Canadian Privacy Act some supporting forms may have been removed from this thesis.

While these forms may be included in the document page count, their removal does not represent any loss of content from the thesis.
Conformément à la loi canadienne sur la protection de la vie privée, quelques formulaires secondaires ont été enlevés de cette thèse.

Bien que ces formulaires aient inclus dans la pagination, il n'y aura aucun contenu manquant. 


\section{Abstract}

The simultaneous production of heat and electricity onsite to serve residential loads can potentially yield a reduction in operating costs, primary energy use and related emissions over traditional technologies which meet these loads separately. Proper sizing and operation of units along with their required buffering and auxiliary systems are critical to the realization of both economical and environmental performance objectives. Further research is required to develop strategies to integrate microcogeneration technologies into Canadian residences as issues related to device type, capacity, design of balance of plant components, and controls remain largely unresolved.

Building performance simulation is a highly flexible, and time-efficient method to systematically explore and evaluate different design options; however, the validity of the conclusions resulting from simulation based studies are dependent on the accuracy and reliability of the models employed. In order to support ongoing research relating to micro-cogeneration technologies through simulation based activities, a facility capable of subjecting units to controlled electrical and thermal loading was designed and commissioned to collect performance data suitable for device-specific model calibration. The facility can also be configured to provide realistic thermal and electrical loading to complete micro-cogeneration systems including thermal storage and auxiliary heating to evaluate the performance of complete systems. It provides a platform to experimentally investigate appropriate configurations to integrate units into residences through variations in the balance of plant components and control strategies.

This thesis describes the design of the facility including its hardware, instrumentation, data acquisition and controls systems. Also described are experiments that were conducted during the commissioning phase to assess system level performance, to identify and correct hardware integration issues, and to determine the physical limitations of the hydraulic test facility. 


\section{Acknowledgments}

I would like to express my appreciation for my colleagues in the Sustainable Building Energy Systems Laboratory. Thank you all for your support and friendship. In particular, thanks to Sebastian Brideau, Skai Edwards, Geoff Johnson, Stephen McMurtry, Briana Paige Kemery and Adam Wills.

I would like to acknowledge the contributions made by Stephanie Seemel and Melina Jefferson during the construction of the facility. I would also like to extend a special thank you to Fred Barrett for his many contributions, valuable advice and continued interest in the project.

I would like to thank my supervisor, Dr. Ian Beausoleil-Morrison for the support and guidance he has provided throughout this work.

Finally, I would like to acknowledge Abbi Slater, her parents, and my family for their unconditional love and support. 


\section{Contents}

$\begin{array}{ll}\text { Abstract } & \text { iii }\end{array}$

Acknowledgments iv

Table of Contents $\quad \mathbf{v}$

List of Tables vii

List of Figures viii

$\begin{array}{ll}\text { Nomenclature } & \text { ix }\end{array}$

1 Introduction 1

1.1 Motivation . . . . . . . . . . . . . . . . 1

1.2 Residential Micro-cogeneration Systems . . . . . . . . . . . 4

1.3 Literature Review . . . . . . . . . . . . . . . 5

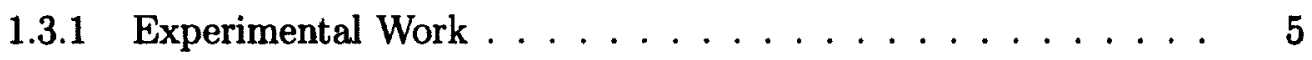

1.3.2 Simulation Based Studies $\ldots \ldots \ldots \ldots$

1.3 .3 Field Trials $\ldots \ldots \ldots \ldots \ldots \ldots \ldots \ldots$

1.4 Thesis Objectives . . . . . . . . . . . . . . . . 17

1.5 Outline of Thesis $\ldots \ldots \ldots \ldots \ldots \ldots \ldots$

2 Description of the Experimental Set-up 19

2.1 Facility Overview . . . . . . . . . . . . . . . . . 19

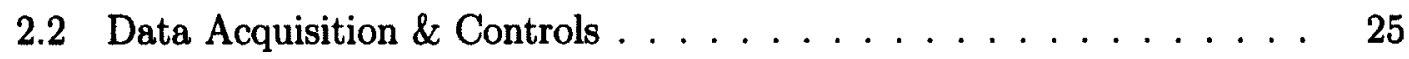

2.3 Test Bench Configurations and Loading . . . . . . . . . . . . 28

3 Instrumentation and Sensor Calibration 32

3.1 Instrumentation . . . . . . . . . . . . . . 32 
3.2 Thermocouple Calibration and Uncertainty . . . . . . . . . . . . 39

3.3 Thermopile Calibration and Uncertainty . . . . . . . . . . . . 42

4 Uncertainty Analysis $\quad \mathbf{4 7}$

4.1 Propagation of Errors into Derived Quantities . . . . . . . . . . 47

4.2 Thermal Power Measurement Bias Error . . . . . . . . . . . . 49

4.3 Thermal Efficiency Bias Error . . . . . . . . . . . . . . 52

4.4 Electrical Power Measurement Bias Error . . . . . . . . . . . . 55

4.5 Micro-cogeneration Efficiency Bias Error . . . . . . . . . . 57

5 Commissioning $\quad 60$

5.1 Controlled Loading . . . . . . . . . . . . . . . 60

5.2 Tank Heat Balance and Sensor Comparison . . . . . . . . 63

5.3 Natural Gas Heater Efficiency . . . . . . . . . . . . . . 66

6 Conclusions and Future Work $\quad 69$

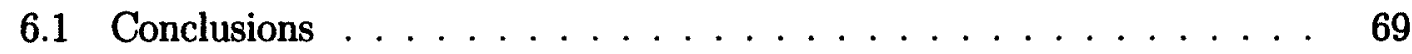

6.2 Future Work . . . . . . . . . . . . . . . . . 70

$\begin{array}{ll}\text { List of References } & 72\end{array}$

$\begin{array}{ll}\text { Appendix A Electrical Drawings } & \mathbf{7 4}\end{array}$

$\begin{array}{lll}\text { Appendix B } & \text { Thermocouple Calibration Data } & \mathbf{7 7}\end{array}$

Appendix C Thermopile Calibration Data $\quad 79$

$\begin{array}{lr}\text { Appendix D Natural Gas Sampling } & 83\end{array}$ 


\section{List of Tables}

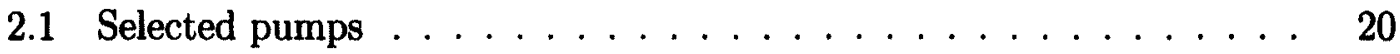

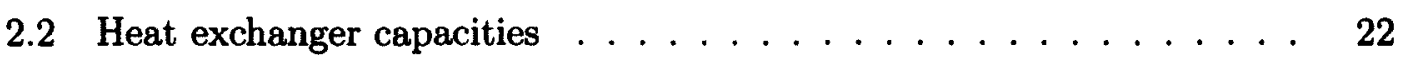

2.3 Electric load specifications . . . . . . . . . . . . . 23

3.1 Flow meter specifications $\ldots \ldots \ldots \ldots \ldots \ldots \ldots$

3.2 Natural gas meter specifications $\ldots \ldots \ldots \ldots \ldots \ldots \ldots$

3.3 Energy meter specifications $\ldots \ldots \ldots \ldots \ldots \ldots$

3.4 Current transducer specifications $\ldots \ldots \ldots \ldots \ldots \ldots$

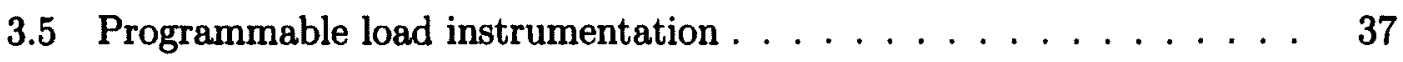

3.6 Temperature sensors specifications . . . . . . . . . . . . 37

3.7 Thermocouple regression equations $\ldots \ldots \ldots \ldots \ldots$

3.8 Thermocouple bias sources . . . . . . . . . . . . . . . 42

3.9 Thermopile regression coefficients $\ldots \ldots \ldots \ldots \ldots \ldots$

3.10 Thermopile bias sources $\ldots \ldots \ldots \ldots \ldots \ldots$

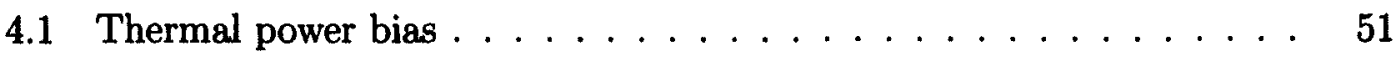

4.2 Thermal efficiency bias errors $\ldots \ldots \ldots \ldots \ldots \ldots \ldots$

4.3 Micro-cogeneration efficiency errors 10-second sampling . . . . . . . 59

4.4 Micro-cogeneration efficiency errors 30-second sampling . . . . . . . 59

4.5 Micro-cogeneration efficiency errors 60-second sampling . . . . . . . 59

5.1 PID control parameters . . . . . . . . . . . . . . 63

5.2 Test bench losses $\ldots \ldots \ldots \ldots \ldots \ldots \ldots \ldots \ldots \ldots$

5.3 Thermal efficiency uncertainty . . . . . . . . . . 68

A.1 Digital ouput channels . . . . . . . . . . . . . 74

B.1 Thermocouple calibration data . . . . . . . . . . . 77

B.2 Thermocouple regression errors $\ldots \ldots \ldots \ldots \ldots \ldots$

C.1 Thermopile calibration data $\ldots \ldots \ldots \ldots \ldots \ldots$

C.2 Thermopile regression coefficients . . . . . . . . . 81 


\section{List of Figures}

1.1 Canadian dwelling types $\ldots \ldots \ldots \ldots \ldots \ldots \ldots$

1.2 Residential energy use distribution $\ldots \ldots \ldots \ldots \ldots$

2.1 Hydraulic test bench . . . . . . . . . . . . . . . 20

2.2 Plant heat transfer paths . . . . . . . . . . . . . . . 21

2.3 Tank and header system $\ldots \ldots \ldots \ldots \ldots \ldots \ldots \ldots \ldots \ldots$

2.4 Test bench hydraulic layout $\ldots \ldots \ldots \ldots \ldots . \ldots 24$

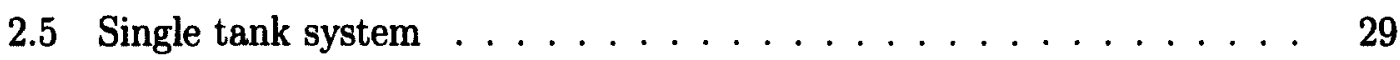

2.6 Two-tank series system . . . . . . . . . . . . . . . . . . . 29

2.7 Two-tank parrallel system $\ldots \ldots \ldots \ldots \ldots \ldots$

2.8 Electrical line diagram $\ldots \ldots \ldots \ldots \ldots \ldots \ldots$

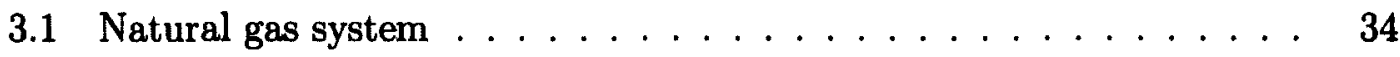

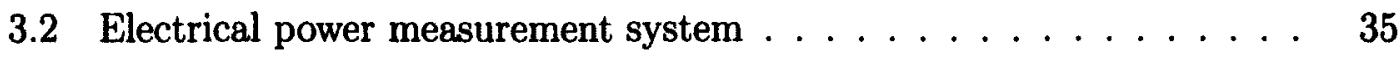

3.3 Compound sensor schematic $\ldots \ldots \ldots \ldots \ldots \ldots$

3.4 Temperature sensor assembly $\ldots \ldots \ldots \ldots \ldots$

3.5 Thermopile calibration map $\ldots \ldots \ldots \ldots \ldots \ldots \ldots$

3.6 Hot-junction temperatures $\ldots \ldots \ldots \ldots \ldots \ldots \ldots$

4.1 Temperature sensor differences . . . . . . . . . . . . 55

5.1 Tank return temperatures $\ldots \ldots \ldots \ldots \ldots \ldots \ldots$

5.2 Rate of heat tranfer to thermal load $\ldots \ldots \ldots \ldots \ldots 62$

5.3 Heat balance experiment configuration . . . . . . . . . . . 64

5.4 Temperature sensor differences . . . . . . . . . . . . 66

5.5 Natural gas heater efficiency $\ldots \ldots \ldots \ldots \ldots \ldots \ldots \ldots$

A.1 Pump relay system $\ldots \ldots \ldots \ldots \ldots \ldots \ldots \ldots$

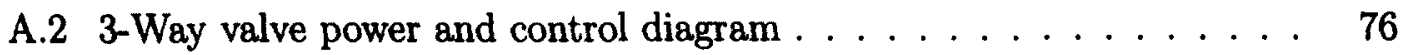

C.1 Thermopile calibration data . . . . . . . . . . . . 80

C.2 Thermopile regression errors $\ldots \ldots \ldots \ldots \ldots \ldots \ldots$ 


\section{Nomenclature}

\begin{tabular}{|c|c|c|}
\hline $\mathrm{AC}$ & alternating current & \\
\hline $\mathrm{B}$ & bias error & \\
\hline GHG & greenhouse gas & \\
\hline $\mathrm{CO}_{2}$ & carbon dioxide & \\
\hline CHP & combined heat and power & \\
\hline $\mathrm{C}_{p}$ & heat capacity & $\mathrm{kJ} / \mathrm{kgK}$ \\
\hline $\mathrm{CSA}$ & Canadian Standards Association & \\
\hline $\mathrm{DAQ}$ & data aquisition and control & \\
\hline $\mathrm{DC}$ & direct current & \\
\hline emf & electromotive force & $\mathrm{mV}$ \\
\hline $\mathrm{FC}$ & fuel cell & \\
\hline F.S. & full scale & \\
\hline $\mathrm{HHV}$ & higher heating value & \\
\hline HVAC & heating ventilation and air conditioning & \\
\hline I & current & Amps \\
\hline ICE & internal combustion engine & \\
\hline $\mathbf{k}$ & pulse rate & \\
\hline LHV & lower heating value & \\
\hline$\dot{m}$ & mass flow rate & $\mathrm{kg} / \mathrm{s}$ \\
\hline
\end{tabular}




\begin{tabular}{|c|c|c|}
\hline $\mathrm{N}$ & number of samples & \\
\hline NIST & National Institute of Standards and Technology & \\
\hline$P$ & pressure & $\mathrm{Pa}$ \\
\hline $\mathrm{PC}$ & personal computer & \\
\hline PCI & peripheral component interconnect & \\
\hline$P_{e}$ & electrical power & $\mathrm{W}$ \\
\hline PID & proportional integral derivative & \\
\hline $\mathrm{Q}_{t h}$ & thermal power & $\mathrm{W}$ \\
\hline $\mathbf{r}$ & derived quantity & \\
\hline $\mathbf{R}$ & resistance & ohms \\
\hline $\bar{S}$ & precision error of a derived quantity & \\
\hline$S$ & standard deviation & \\
\hline $\mathrm{SE}$ & stirling engine & \\
\hline $\mathrm{S}_{i}$ & precision error & \\
\hline SLE & special limits of error & \\
\hline RTD & resistance temperature detector & \\
\hline $\mathrm{t}$ & student t statistic & \\
\hline $\mathrm{T}$ & temperature & ${ }^{\circ} \mathrm{C}$ \\
\hline $\mathrm{TC}$ & thermocouple & \\
\hline $\mathrm{TP}$ & thermopile & \\
\hline $\bar{U}$ & uncertainty margin & \\
\hline $\mathrm{V}$ & voltage & $\mathrm{V}$ \\
\hline$\dot{V}$ & volumetric flow rate & $\mathrm{m}^{3} / \mathrm{s}$ \\
\hline
\end{tabular}




\section{Subscripts}

$\begin{array}{ll}\text { a } & \text { accuracy } \\ \mathrm{p} & \text { pulse } \\ \mathrm{BL} & \text { blue } \\ \mathrm{BR} & \text { brown } \\ \mathrm{CJ} & \text { cold-junction } \\ \mathrm{e} & \text { electric } \\ \mathrm{E} & \text { energy meter } \\ \mathrm{g} & \text { gas } \\ \mathrm{HJ} & \text { hot-junction } \\ \mathrm{m} & \text { molar basis } \\ \mathrm{T} & \text { total } \\ \text { th } & \text { thermal }\end{array}$

\section{Greek Symbols}

$\eta$

efficiency

$\theta$

sensitivity factor 


\section{Chapter 1}

\section{Introduction}

\subsection{Motivation}

In Canada, in the year 2007, there were almost 13 million residences housing a population of roughly 32 million people. The residential sector alone accounts for $17 \%$ of all secondary energy consumed and produced roughly $15 \%$ of national greenhouse gas (GHG) emissions [1]. Figure 1.1 shows the distribution of dwellings by type based on data collected for the Survey on Household Energy Use [2]. The figure shows that the majority of the housing stock fell within only two housing types. Slightly more than half of the housing stock consists of single detached homes which consumed over $75 \%$ of the energy used in the residential sector. When taken together, single detached and double/row houses accounted for over $88 \%$ of all residential energy consumption. This result is significant as it indicates that efforts to reduce energy demand and emissions within this sector should target these dwelling types.

Since 1990 , residential energy consumption has grown by almost $10.8 \%$ despite a reduction in energy intensity of $25 \% / \mathrm{m}^{2}$ of occupied living space. The increase in consumption has been driven primarily by population growth accompanied by reduced occupancy per household resulting in a need to build more homes. An increase in average occupied living space, a doubling of floor space being cooled and an increase in the number of electrical appliances per home also contributed strongly [1]. Emissions from the residential sector have decreased by approximately $5.8 \%$ between the years 1990 and 2010, however it is important to note that the demand for energy and the resulting emissions are very sensitive to variations in weather fromyear to year. For example, when the energy consumption trend is adjusted to account for the difference 


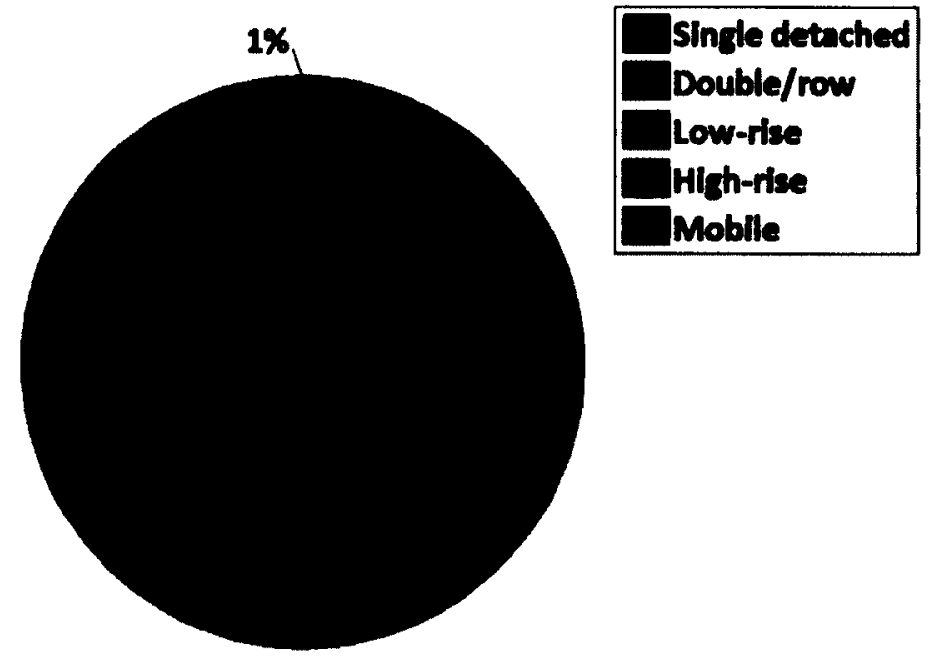

Figure 1.1: Canadian dwelling types

between the heating degree days to compensate for the yearly variations between heating seasons, a net increase of $1.7 \%$ can be observed [3].

Energy consumption and related emissions originating from a home depend on a large number of factors including: the size, age and type of residence, the number of occupants, the regional availability of fuels and the local climate. The amount of energy used to power electrical appliances and to provide space conditioning or domestic hot water is dependent on household demand for these services and the efficiency of the technologies used to deliver them. Figure 1.2 shows the distribution of residential energy used in an average home. Together, space and water heating are responsible for $80 \%$ of the total energy consumed within a home. The remaining $20 \%$ consists almost exclusively of electricity used for appliances, lighting and space cooling.

Although electricity use only accounted for a small portion of the energy used in most homes, its consumption often results in a disproportionate production of GHG emissions. When electricity is produced by fossil fuel based generation and transported to end users through a provincial distribution system, the GHG intensity per unit of electrical energy consumed within the home is typically larger than that 


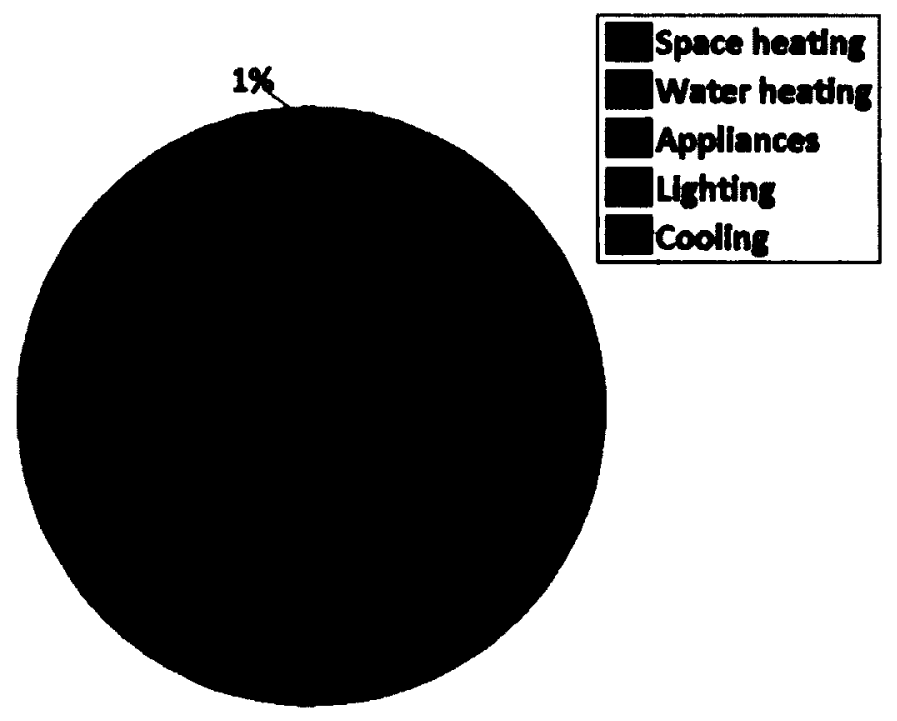

Figure 1.2: Residential energy use distribution

for the production of a unit of heat on-site. Although the emission intensity and primary energy consumption for residential electricity depends to a large extent on the provincial electricity mix and is known to vary over the course of a day and seasonally, displacing a portion of this energy using other means such as distributed generation may result in improved environmental performance.

The co-production of both heat and electricity from a single fuel source on-site, often referred to as cogeneration, is an example of a distributed generation technology which could potentially provide a meaningful reduction of energy use and related emissions. Typically, only the emissions of carbon dioxide $\left(\mathrm{CO}_{2}\right)$ are considered when comparing the environmental performance of congeneration systems to other technologies, but a more complete analysis would have to consider the release of unburned hydrocarbons, the production of nitrous oxides and particulate matter. It is also notable that the production of electrical power on-site shifts the point of emissions from centralised facilities which are typically built in remote areas to the homes which consume this energy. Cogeneration technologies designed for operation on a residential scale (micro-cogeneration) have yet to reach maturity and significant research must be undertaken to determine the effect of widespread deployment within the Canadian residential sector. 


\subsection{Residential Micro-cogeneration Systems}

The simultaneous production of heat and electricity at the residential scale can potentiality yield a reduction in operating costs, primary energy use and related emissions when compared to the typical arrangement where electricity is generated centrally and heat is produced locally using a boiler or furnace. A number of technologies have been developed for residential micro-generation systems including combustions-based systems employing either internal combustion engines (ICE) or Stirling engines (SE) and fuel cell (FC) based systems. The capacity of these devices is typically characterized by the net $\mathrm{AC}$ electrical output which can range between $1 \mathrm{~kW}-15 \mathrm{~kW}$. Typical electrical conversion efficiencies can vary widely between devices ranging from as little as $5 \%$ to as high as $45 \%$ for some modern fuel cell systems. Electrical efficiency is typically quoted as the net AC power produced as a percentage of the source fuel's lower heating value (LHV). Total efficiencies greater than $90 \%$ are achievable in systems where heat recovery permits the condensation of vapour in the exhaust gas stream but average efficiencies over an entire year can often be significantly lower. The total efficiency of micro-cogeneration devices is defined here as the sum of the net electrical and thermal power as a percentage of the source fuel's LHV.

Generally speaking, micro-cogeneration devices are operated in two ways: systems can be controlled by means of a heat led strategy where the device is activated based on a need for thermal energy (typically using a thermostat) or systems capable of modulating their output can be controlled to meet the electrical demand of the residence. Ultimately, configuring the device to follow a particular load type will result in either an over or under production of the other form of energy being coproduced. Electrically led systems typically employ some means of thermal storage in order to accommodate the difference between production and household demand for heat. Many of the devices currently available are designed to be grid-tied, providing unlimited electrical buffering. Battery storage systems are also a possibility for standalone systems or strategies to minimize grid interaction and reduce peak electrical demand.

Systems can be sized to satisfy the entire yearly demand for both heat and electricity, the complete demand for one quantity and a portion of the other, or most commonly, a portion of both loads. For the latter two configurations, auxiliary heating systems may be required to supplement the output from the micro-cogeneration device in order to ensure thermal comfort. Thermally led systems which are oversized 
experience significant losses from repeated cycling while electrically led devices can suffer from a linear decrease in efficiency when operating under part load.

Despite the fact that thermal efficiency of a micro-cogeneration device is often less than that of a boiler or furnace providing heat locally, an overall increase in energy efficiency often is possible when compared to the conventional methods of generating heat and electricity separately. In order to fully realise this improvement, the system must be properly configured to ensure maximum utilization of thermal energy. Optimizing the configuration of a micro-cogeneration system for even a single home can be challenging because the thermal loads exhibit both significant long term seasonal variations and shorter diurnal cycles. The net benefit of micro-cogeneration systems over that of conventional technologies is dependent to a large extent on geographical conditions such as the local climate and electricity mix, occupancy driven loads for electricity and hot water, and thermal characteristics of the home. Proper sizing and operation of units along with the required buffering and auxiliary systems is critical to the realization of both economical and environmental performance objectives.

Given the complexity of micro-cogeneration systems and their sensitivity to a large number of factors, a systematic approach to design, integration and control is needed to adequately explore and evaluate suitable configurations.

The tools available to researchers and building scientists to study microcogeneration include computer simulation, experimental testing and field trials. Each of the aforementioned approaches has a unique set of merits and limitations making them useful within a specific context. The concurrent use of more than a single tool is often necessary to develop a realistic understanding of the problem and to generate meaningful solutions. The following sections aim to summarize the relevant work undertaken using each approach and discuss if and how these results can be extended to make generalizations relating to the integration and performance of micro-cogeneration within a Canadian context.

\subsection{Literature Review}

\subsubsection{Experimental Work}

Experimental investigation of micro-cogeneration devices is required to provide the fundamental data needed to fully characterise the performance of units over the course of their development from prototypes to mass production of commercially available 
devices. Testing of prototype devices allows designers to access the technical feasibility of different design options and provides valuable information relating to controls and hardware integration. Experimental testing of commercially available devices is essential because specification sheets rarely provide the level of detailed information that is required to assess their performance over a broad range of operating conditions. Typically, manufacturers provide specifications for capacity and efficiency of units operating under steady state conditions at the point of highest electrical efficiency. The operation under part load, during transient conditions such as start-up and shut down, and operation under off-design conditions may differ considerably from the point of best performance.

Some of the largest contributions to the research and development of residential micro-cogeneration systems consisted of work undertaken by a multi-national research project known as Annex 42 operating under the auspices of the International Energy Agency Energy Conservation in Buildings and Community Systems Programme. The Annex carried out specific research objectives related to the advancement of design, operation and analysis of micro-cogeneration systems. One of the particular goals was to determine the technical, environmental and economic performance of microcogenerations systems using whole building simulation tools. A significant volume of research was conducted over a 5 year period and is summarized in a final report [4].

A detailed review of micro-cogeneration models undertaken by the Annex found that very few existing models treated systems with an appropriate level of detail and were suitable for integration within whole building simulation programs. In light of this, there was a need to develop, calibrate and validate device specific simulation models which could be integrated in existing simulation tools. A grey box approach was adopted to create flexible models for both fuel cell and combustion-based devices. Because the models are semi-empirical, their calibration requires performance data from real units operating under both steady state and dynamic conditions. A standardized experimental protocol was developed and work to characterize 13 individual micro-cogeneration devices was completed at 7 different facilities. A complete description of the facilities, the devices tested and experimental work undertaken can be found in [5].

A number of investigations did not adhere completely to the protocol as they were carried out prior to its development, while a number of experiments could only collect limited data due to physical limitations of the facilities. Furthermore, instrumentation 
bias on measured quantities and its propagation into derived performance metrics was not rigorously documented. Although the functional from of the models can capture the behaviour of a device over its entire range of operation, the accuracy of their predictions is limited by the accuracy of the measurements taken during calibration experiments. It's important that efforts are made to quantify and reduce the measurement uncertainty which is ultimately propagated into simulation results in order ensure that predictions can be made with confidence.

In 2003, the Canadian Center for Housing Technology (CCHT) began modifications to its experimental facilities to examine the performance of emerging and market ready residential cogeneration systems. The facility consists of two identical, heavily instrumented research houses with realistic simulated occupancy [6]. The research houses provide an opportunity to draw a direct comparison between the performance of common residential technologies (installed in one of the homes) and novel ones such as micro-cogeneration devices. The facility was designed to provide an intermediate experimental environment between that of a typical laboratory test bench and a full field trial.

The first micro-cogeneration device tested at the facility was a prototype natural gas fired Stirling engine rated at $750 \mathrm{~W}_{e}$ AC. The unit was operated over a period of 3.5 months from March to mid-June and was configured to operate under a heat lead regime. To complete the balance of plant components, a secondary $150 \mathrm{~L}$ hot water storage tank was added which could be charged in series or in parallel with the existing domestic hot water tank. A fan coil forced air system was used to provide space heating. Both plant configurations considered were capable of meeting the entire space and hot water heating loads. The difference in the average efficiencies between both plant configurations calculated at either the device or system level was less than $2 \%$. The results show a significant reduction in performance when comparing the efficiency of the unit alone to the efficiency of the entire system. The mean efficiency (total) of the device over the entire test was $81.9 \%$ while the total system efficiency was only $48.8 \%$. The losses were attributed to the cycling of the unit, standby losses from the thermal storages and sub-optimal control of the plant. Heat lead operation of the unit also resulted in significant periods where electricity was either imported or exported to the grid Stirling. Although the electrical use of the pumps accounted for less than $1 \%$ of the total system output, their operation further reduced the electrical output by $12.4 \%$. Overall the results indicated that 
improved control and design of the balance of plant components could significantly improve the system level performance. A detailed description of the instrumentation was not provided, nor were uncertainty margins for reported quantities.

Since the initial installation in 2003, a number of other micro-cogeneration technologies have been installed and monitored at the CCHT twin house facility [7]. Over a five year period, a fourth generation SE system [8], a solid oxide FC [9], a hybrid ICE/ high-efficiency furnace system [10], and a larger ICE system coupled to a ground loop and heat pumps were analyzed [11]. The Stirling engine system was installed in the facility's information center where it operated over the 2004-2005 heating season, while the fuel cell was installed in one of the twin houses where it provided a continuous output of $2.2 \mathrm{~kW}_{e}$ during the spring of 2005 . The hybrid furnace system which had a thermal output of either $3.25 \mathrm{~kW}$ or $18 \mathrm{~kW}$ was installed and operated during the 2007 heating season. The performance of this system was compared to the reference house based on energy consumption and operating costs over the testing period.

Generalizations concerning the different installations are difficult to make because of the fundamental differences among the device types and the relatively large range of capacities. The systems tested were also in different stages of development favouring those which are closer to maturity. Continued research regarding thermal storage, heat utilization, supplementary heating systems, and controls suitable for forced air systems must be undertaken to address integration of units into Canadian homes. The large discrepancy between the heating loads observed during the winter and summer season also poses a significant challenge in terms of design and operation. Despite its technical feasibility, the integration of units designed for operation in other countries often results in operation at lowered efficiency leading to poor performance. Experimentation within the homes allows researchers and manufacturers to develop an understanding of the practical barriers related to the integration and operation of innovative technologies. An assessment of performance is possible using this approach, but the results are specific to the configuration chosen, the length and weather conditions during the monitoring period, and the characteristics of the test home.

Although running experiments over a relatively short period of time can provide valuable information to researchers and manufacturers, economic and environmental performance is typically determined over a period of a single year or several years. For 
the most part, it is impractical to run experimental tests in a laboratory setting for such lengthy periods. In light of this, an attempt has been made to project the results from typical day types simulated on a test bench to annual values by correlating annual heating loads to the outdoor temperature [12]. The three different devices considered for the study were a variable power ICE device with a rated output of 1.3 $\mathrm{kW}_{e}-4.7 \mathrm{~kW}_{e}$, an ICE device with a constant output of $5 \mathrm{~kW}_{e}$ and an SE capable of modulating its electrical production between $2 \mathrm{~kW}-7.5 \mathrm{~kW}$. Each unit was tested on the bench using load profiles from a measuring campaign monitoring various types of residences in Germany. Typical days for the summer, shoulder season, and winter were reproduced on the rig to provide realistic dynamic loading. A description of the facility and instrumentation can be found in [5], but no formal uncertainty analysis regarding measured or derived quantities was provided. The buildings simulated were sized so that the units provided roughly $25 \%$ of the peak heat load. The results show that the units ran for $\mathbf{4 0 0 0}$ - $\mathbf{5 0 0 0}$ hours annually and were capable of providing $66 \%-85 \%$ of the annual heat demand. Total efficiencies ranged between $90.0 \%-91.3 \%$ based on the adopted load profile and buffering scheme chosen. Information regarding the fraction of electricity imported/exported was not available.

Although a number of assumptions had to be made to extend the typical day type analysis to yearly projections, the results indicate that high overall efficiencies are possible when units had been sized to cover only a small portion of the peak heating load. If the units were sized to cover a greater portion of the load, larger differences would be likely observed due to cycling. This type of analysis is more suitable to match particular units to buildings in the early stages of a field trial or to estimate the impact of applying these technologies to a subset of the building stock.

\subsubsection{Simulation Based Studies}

Exploring the performance of residential cogeneration systems through computerbased simulation holds many advantages over other means such as experimental studies and field trials. Simulation based studies are a relatively inexpensive, highlyflexible, and time efficient method to investigate strategies to successfully integrate and operate micro-cogeneration technologies. Parametric studies can be used to identify and determine the sensitivity of any number of factors including the configuration and control of the balance of plant components, the effects of occupant driven loads, modifications made to the building envelope, and the effects of geographical/local 
conditions. Annual simulations are most often performed to determine how well particular solutions perform against a well established baseline technology. Shorter simulations are useful to access issues related to thermal comfort or the dynamic behaviour at a system level.

The results from computer-based simulation studies must be carefully scrutinized because they are sensitive to the quality of that data used to drive the simulation and the assumptions used throughout the modelling. Models varying in complexity from simple steady-state performance maps to detailed models capturing inertial effects or electro-chemical and combustion reactions within sub-components have been created. Some models must be driven exclusively by external load profiles and run independently while others such as those developed as part of Annex 42, can be integrated into the subroutines of existing whole building simulation tools [4]. The level of detail that is appropriate depends to some extent on the objectives of the simulation and the required accuracy of its results. In the case where coupling to a building and its HVAC system is desired, the transient response of the device must be represented and the time step selected should be relatively short. Varying the temporal precision of the load demand data served by a micro-cogeneration device between 1 hour and 5 minutes can have a significant effect on performance. It was shown that the fraction of the heat supplied by an auxiliary boiler varied by $40 \%$ and the reduction in emissions observed could be overestimated by as much as $40 \%$. The economics were somewhat less sensitive but the results indicated an increase in cost of roughly $8 \%$ over the life of a system [13].

A later study showed that environmental and economic performance of residential cogeneration systems was sensitive to the amount of energy consumed during start-up and shut down periods. A mixed integer linear programming approach was used to minimize the annual cost of meeting specific residential electricity and heat demand profiles. It is notable that much of that data used for start-up and shut down energy consumption had to be assumed or scaled from units of other capacities. This serves to illustrate the lack of reliable performance data available in the literature. To account for this, start-up energy consumptions was varied widely to investigate the sensitivity to this parameter. The results demonstrated that devices with higher heat to power ratios such as SE and ICE experience a greater number of cycles resulting in significant losses over an annual period. This provides an indication that start-up and shut down behaviour should be treated by models especially if the device is expected 
to operated intermittently [14].

As part of the Annex 42 initiative, a parametric study was conducted to analyze the performance of a prototype SE and a solid oxide FC in Canada [15]. Both models were calibrated and validated using data from experimental testing and were simulated using the ESP-r whole building simulation program. A large number of parameters were varied including control strategies, thermal buffering, building heat load and electricity demand and geographical location. Environmental performance was assessed by comparing primary energy use and emissions generated to that of a reference system using location specific electricity data. The results pertaining to the SE simulations indicate that heat led operation always resulted in better performance then electrically led control. The results were most sensitive to the volume of the thermal buffer as this component accounted for the largest losses in efficiency $(10 \%)$ calculated between the device and system level. Performance generally increased with increasing heating loads. Parasitic losses represented almost $20 \%$ of the device electrical output at full load, and in some cases where there was little demand for heat; these losses were actually larger than the device's electrical output. The annual emissions from the SE ranged from a decrease of $1 \%$ to an increase of roughly $2 \%$ depending on the case considered. Primary energy consumption increased between 5 $-10 \%$ for the cases that were heat led.

The FC system was simulated to run continuously at maximum capacity which resulted in a need to dump as much as $60 \%$ of its thermal output. This is significant considering the unit was not used during the summer months. Operation under this regime greatly reduced the efficiency of the device and lead to significant electricity exports. As with the SE system, the variation in tank size proved to be the most sensitive parameter followed by the household demand for heat and electricity. Almost all cases considered resulted in net reduction of emissions. The observed reductions were between $5 \%$ and $22 \%$. Annual natural gas consumption was increased between $50 \%$ and $150 \%$ for the cases considered mainly due to the need to dump heat. It is clear from the simulation work that the efficiency of the devices (both SE and FC) must be improved and the storage and balance of plant components must be further optimized to yield both primary energy and emissions reductions. They also indicate that micro-cogeneration systems may not be viable in low energy demand residences and that environmental performance is sensitive to the choice of reference technologies. Both system models were calibrated using performance data from early 
prototype devices. Lessons learned from simulation work can help inform the design of new systems more suitable for operation in the Canadian setting. A simulationbased assessment of their performance would require experimental calibration and validation of the improved units.

The work previously described underestimates the performance that could be achieved using a SE system, as the prototype unit considered had a significantly lower efficiency than that expected from a mature market-ready technology. Another simulation-based study was undertaken to estimate the performance of a mature SE technology deployed in a single family home in Canada [16]. The unit simulated for this study was assumed to have a maximum capacity of $1 \mathrm{~kW}_{e}$ generated at $12.5 \%$ efficiency with respect to the fuel's HHV. Power consumption of the device was reduced to just $9 \mathrm{~W}$ during stand-by conditions and $100 \mathrm{~W}$ during operation. It was also assumed that the heat recovery system was capable of condensing water vapour in the exhaust stream increasing the unit's total efficiency to $92 \%$. The efficiency of the thermal storage tank was improved by increasing the insulation level. The system was simulated in a typical single family home having a heating load of 71 GJ per year located in a city with a relatively high emission factor for electrical power. The electricity produced was assumed to displace the emissions from a single-cycle peaking gas-turbine generation station rated at $36 \%$ efficiency during the mid-peak and on-peak periods while an on-the-margin approach was adopted for off-peak hours. The results show that a mature device with improved storage can reduce emissions by $17 \%$ and is capable of reducing primary energy demand (by $2.3 \%$ ) when compared to the most efficient fossil generation technologies.

The improvement over the base case would be less pronounced for buildings having a smaller heat load and residences served by electricity generated using a larger proportion of emission-free power. Nonetheless, the study demonstrates that significant improvements are possible with modest improvements to SE devices and the use of more common approaches such as improving insulation in tanks and using DC motors to drive pumps or fans. Experimental testing of mature units would ultimately be required to confirm the performance improvements assumed in the simulation.

The performance of electrically led ICE-based systems operating in single detached homes has been simulated across a number of locations in Canada [17]. Three houses each representing a particular vintage were chosen for each province to capture a representative sample of the housing stock. Each house was simulated with two 
different units having a capacity of either $1 \mathrm{~kW}_{e}$ or $2 \mathrm{~kW}_{e}$ and a storage tank of either $300 \mathrm{~L}$ or $400 \mathrm{~L}$. The greenhouse gas emissions and energy costs were calculated relative to a base case consisting of a forced air furnace, standard domestic hot water tank, and grid electricity. Electricity profiles from a measuring campaign were roughly matched to houses across the country based on the physical characteristic of the buildings and their occupancy. The selected profiles were averaged and normalized to be incorporated into the 15 minute time steps used in the study. Both flat-rate and time-of- use costing was used for the price of electricity. A profile developed by the Canadian Standards Association (CSA) for testing of solar domestic hot water systems was adopted for the simulation. The electrically-led operation of the larger unit suffered from reduced efficiency because large amounts of heat were rejected to prevent overheating of the storage tank.

Although the efficiency of the smaller unit was higher due to better heat utilization and reduced operation under part load, annual energy costs were higher than those of the base case for all configurations. A reduction in emissions was observed only when the emission intensity of the grid was above $400 \mathrm{~g}$ of $\mathrm{CO}_{2} / \mathrm{kWh}$. Electrically led control of such units is not ideal and the results were largely sensitive to the household energy demand and the grid electricity signature. Performance data from a larger $6 \mathrm{~kW}$ engine was scaled down as calibration data was not available for the chosen units. The total efficiency of the devices was held constant at $80 \%$ while the fuel consumption and electrical efficiency were varied under part-load conditions using second and third order polynomials. This simple treatment likely does not completely capture performance degradation resulting from cycling. A heat led assessment using calibrated models having the desired capacity would provide a more realistic estimate of the possible reductions in cost and emissions.

The performance of a hybrid multifunctional heating system consisting of SE cogeneration device coupled with a thermal storage tank, a backup burner, a forced air furnace, and a solar thermal system has also been investigated [18]. The SE engine model was calibrated using experimental data and the house model was calibrated to match a research house and then modified to reflect the construction of an average Canadian home. For this study, a system configuration without solar thermal heat was chosen for the base case. The production of both heat and electricity from all sources was assumed to come from natural gas with a single emissions factor allowing reductions in natural gas or greenhouse gas emissions to be used interchangeably. 
Four separate configurations were evaluated to determine the possible reductions resulting from the inclusion of solar heat. For the first two cases considered, the solar energy only contributed to water heating while the third and fourth case allowed the collectors to contribute to space heating as well. The systems where solar energy was used for both heat loads incorporate 4 flat plate collectors while the others only had 2 collectors. The second and fourth cases also incorporated an additional solar buffer tank.

The results from the first two cases show a decrease in consumption of $9.5 \%$ and $11.6 \%$ relative to the base case. Cases three and four resulted in slightly better performance providing reductions of 10.8 and $10 \%$. Two of the systems (2 and 3) were simulated in 4 four different Canadian cities however only small changes were observed as only the weather driven parameters were changed. A doubling of the collector area was examined which resulted in significantly more thermal energy collection but also increased storage losses and reduced SE performance. The net effect was only a modest reduction in emissions of roughly $2 \%$. When the storage volume was doubled, a further reduction of only $0.5 \%$ was possible for the cases with solar energy while the base case actually had an increase of $0.7 \%$. Micro-cogeneration devices, their associated balance of plant components and auxiliary heating units are relatively complex systems which can be difficult to configure and operate optimally. The inclusion of solar energy systems adds another level of complexity in terms of integration and control. The results of this work suggest that that such systems may be sensitive to a number of parameters, and that only a small subset of all design configurations and control strategies have been evaluated as indicated by the authors. Once suitable configurations have been identified through simulation work, they could be reproduced experimentally in an effort to validate system level performance.

\subsubsection{Field Trials}

Field trials allow researchers and manufacturers to examine the performance of products operating under actual conditions rather than those approximated by a test bench or a computer simulation. They often provide valuable information related to product installation in retrofit applications and issues associated with grid connection. Most field tests are conducted over periods long enough to make an assessment of the reliability of units and more importantly, discover failure mechanisms which can be corrected before mass production. Field tests should be carefully designed to 
record not only performance based metrics but also other relevant parameters unique to each installation in order to allow differences between individual cases to be understood. Larger field trials can be relatively expensive compared to simulation based studies and their execution requires significant planning and resources. Because of this, field trials are typically conducted by a number of partners in countries having policies supporting their adoption. To date, there has not been a large field trial for micro-cogeneration systems in Canada and there is little financial support for those wishing to develop or install such systems. Although results from field trials in other countries can not be applied directly in other jurisdictions, practical lessons learned can support research efforts or inform upon the design of a Canadian field trial.

A field trial carried out in Flanders was undertaken to examine the performance of an ICE based cogeneration system installed in a multi family-home [19]. An existing apartment block consisting of 12 units was renovated to perform above the building code by increasing insulation, adding heat recovery to the ventilation system and including a solar domestic hot water system. The $5.5 \mathrm{~kW}_{e}$ unit was used with a simple on/off control and was operated in parallel with a $100 \mathrm{~kW}$ condensing boiler. Energy consumption and production from all the systems was measured at 15 minute intervals for a period of two years. Relatively poor performance was observed during the first year leading to modifications in the hydraulic layout and control strategies. During the second trial run, the unit ran for 3645 hours producing $44 \%$ of the total heat demand. The unit did not supply heat during the months of June - August. The unit produced $18,554 \mathrm{kWh}$ of electricity in addition to the $146 \mathrm{kWh}$ consumed by the HVAC system during the second trial. The annual average electrical and thermal efficiencies were calculated to $24.3 \%$ and $58 \%$ relative to the lower heating value for natural gas. The inclusion of the system reduced primary energy consumption by $19 \%$ and had a simple payback period of 8 years or 3 years with the inclusion of government subsidies. This type of installation could be used as a means of introducing the technology into the residential sector because of its high efficiency and relatively short payback period.

The Institute of Energy Economy and Application Technology and a local gas supplier in Germany jointly conducted a field trial to examine the performance of SE systems operating in single family homes [20]. Four homes each having an average annual electrical consumption of $5000 \mathrm{kWh}$ and a combined heat load of $30,000 \mathrm{kWh}$, were chosen to assess the performance of a $1 \mathrm{~kW}_{e}$ electric SE system with an internal 
$18 \mathrm{~kW}$ backup burner. Two of the homes were equipped with a $750 \mathrm{~L}$ tank providing buffering for both hot water and space heating while the remaining two installations employed a $200 \mathrm{~L}$ hot water tank heated with an internal heat exchanger with space heat provided directly from the SE unit. Energetic flows were measured at 1 second intervals for an entire year providing excellent resolution of performance data. Electrical import/export was only measured for one installation and only the net power from the SE could be measured. Two of the units had large annual runtimes of 4149 hours and 5118 hours but the other two installations had reduced operation due to frequent breakdowns. The average electrical and thermal efficiencies over the trials were calculated to be $12.2 \%$ and $79 \%$. Total efficiency under full load was above $90 \%$ which was consistent with the manufacturer's claims. The more complex configuration with the larger buffer tank resulted in longer runtimes allowing the units to operate closer to peak efficiency.

The UK Carbon Trust's Micro CHP Accelerator led a number of initiatives to better understand the potential of micro-cogeneration technologies as a method to reduce emissions in the residential and commercial sector. The final report describes a large field trial where SE systems were installed and monitored in 72 homes for 3 years beginning in 2005 [21]. A representative sample of the housing stock was chosen to investigate effects related to age, type and location. Relevant energetic flows were measured and recorded at 5 minute intervals. To establish a baseline, 36 homes heated with high-efficiency boilers rated at or above $90 \%$ efficiency were also monitored. The results show that boilers typically operated about $5 \%$ below their rating due non-condensing conditions and over sizing.

The aggregate average carbon savings from the SE systems were close to $5 \%$ but ranged between $-4 \%$ and $12 \%$, depending mostly on the heat demand of the home. Homes having a heating load larger than $15,000 \mathrm{kWh}$ per year experienced carbon savings ranging between $4 \%-14 \%$. Even with a generous feed-in tariff for electricity exports, a payback period of roughly 16 years is expected based on an annual heat demand of $20,000 \mathrm{kWh}$ and $€ 2,500$ cost premium over a boiler system. Smaller houses had payback periods of over 30 years which is longer than the expected life of most systems. Increasing the average electrical efficiency from $6 \%$ to $9 \%$ was shown to halve the payback period for most cases making the investment much more attractive.

Another interesting result was that differences in the carbon reduction ratio for homes with similar heat loads and identical SE units were as large as $15 \%$. This 
suggests that integration and control of the units plays an important role in optimizing their performance. To put the field trial results into perspective, the average heating load for a detached home in Canada is roughly $19,800 \mathrm{kWh}$ indicating that SE based cogeneration may provide significant savings. The trends observed in the data reduction are consistent with those from simulation-based studies.

The potential reduction in primary energy use and emissions resulting from the adoption of micro-cogeneration technologies within Canada has not been fully explored. Issues regarding the choice of device type, their capacity, control strategy and configuration of auxiliary systems have yet to be resolved. Experimental investigation of the performance of micro-cogeneration units is required to continue supporting simulation-based studies through calibration and validation of device specific models. Experimental-based studies subjecting units to realistic building loads can also be used to identify suitable configurations for specific sectors of the building stock. Together, simulation and experimental work can be used to illustrate the potential of these technologies and provide motivation for large scale field trials. The following section will describe the objectives of this research and how it can contribute to the advancement of micro-cogeneration technologies.

\subsection{Thesis Objectives}

The overall objective of this research was to design, commission and test a facility to experimentally study the performance of micro-cogeneration systems operating under controlled conditions. The specific objectives driving the development of the facility were the following:

- Commission a facility capable of providing controlled thermal and electrical operating conditions required to generate and collect data suitable for model calibration or performance mapping of micro-cogeneration devices

- Develop a hydraulic test bench to experimentally investigate appropriate configurations to integrate micro-cogeneration units into residences through variations in the balance of plant components and control strategies

- Provide realistic controlled thermal or electrical loading to micro-cogeneration devices, with variable thermal storage and auxiliary heating systems 
- Evaluate and compare the performance of single or two-tank variable volume systems and develop strategies for charging /discharging that promote thermal stratification

- Simulate the thermal output of micro-cogeneration devices of varying capacities with novel control methods to better match thermal energy production with seasonal energy demands of homes

\subsection{Outline of Thesis}

This thesis describes the experimental design and operation of a facility capable of characterising the performance of micro-cogeneration devices and complete microcogeneration systems used to serve residential loads. The next chapter provides an overview of the facility, describes how it can be configured, and explains the hardware selected for control and data acquisition. Following this, the instrumentation chosen is described followed by an uncertainty analysis providing uncertainty margins for all measured and derived quantities recorded in the facility. Finally, a number of experiments conducted during the commissioning phase to assess the facility's performance and determine its limitations are presented. 


\section{Chapter 2}

\section{Description of the Experimental Set-up}

This chapter contains a description of the experimental facility designed to test microcogeneration systems. It will begin with an overview of the facility and will provide the specifications of all the plant level hardware selected. The platform and strategies chosen to integrate and control the facility's hardware and data aquisition systems will be explained. The chapter will close with a description of how the test bench can be configured to meet the research objectives previously identified.

\subsection{Facility Overview}

This section will provide a broad overview of the testing facility and will present a brief description of the components selected for each sub-system. The hydraulic test bench consists of a number of fluid circuits allowing heat transfer between a cogeneration device, two variable volume thermal buffers, supplementary heating systems, and thermal loads. The circuits consist of 0.75 inch copper tubing which has been insulated to minimize heat loss to the ambient environment. Figure 2.1 shows a photograph of the test bench while Figure 2.4 illustrates the complete hydraulic layout of the facility. The labels shown in this figure will be used to refer to specific components and instrumentation throughout the remainder of this work. The relative position of each component is shown in this schematic and individual circuits have been identified using a color coding scheme. A large number of configurations are possible and can be selected by changing the position of the 11 electronically-actuated, computer-controlled 3-way ball valves (S1-S11).

A total of 4 vertical multistage centrifugal pumps were needed to realize the heat 

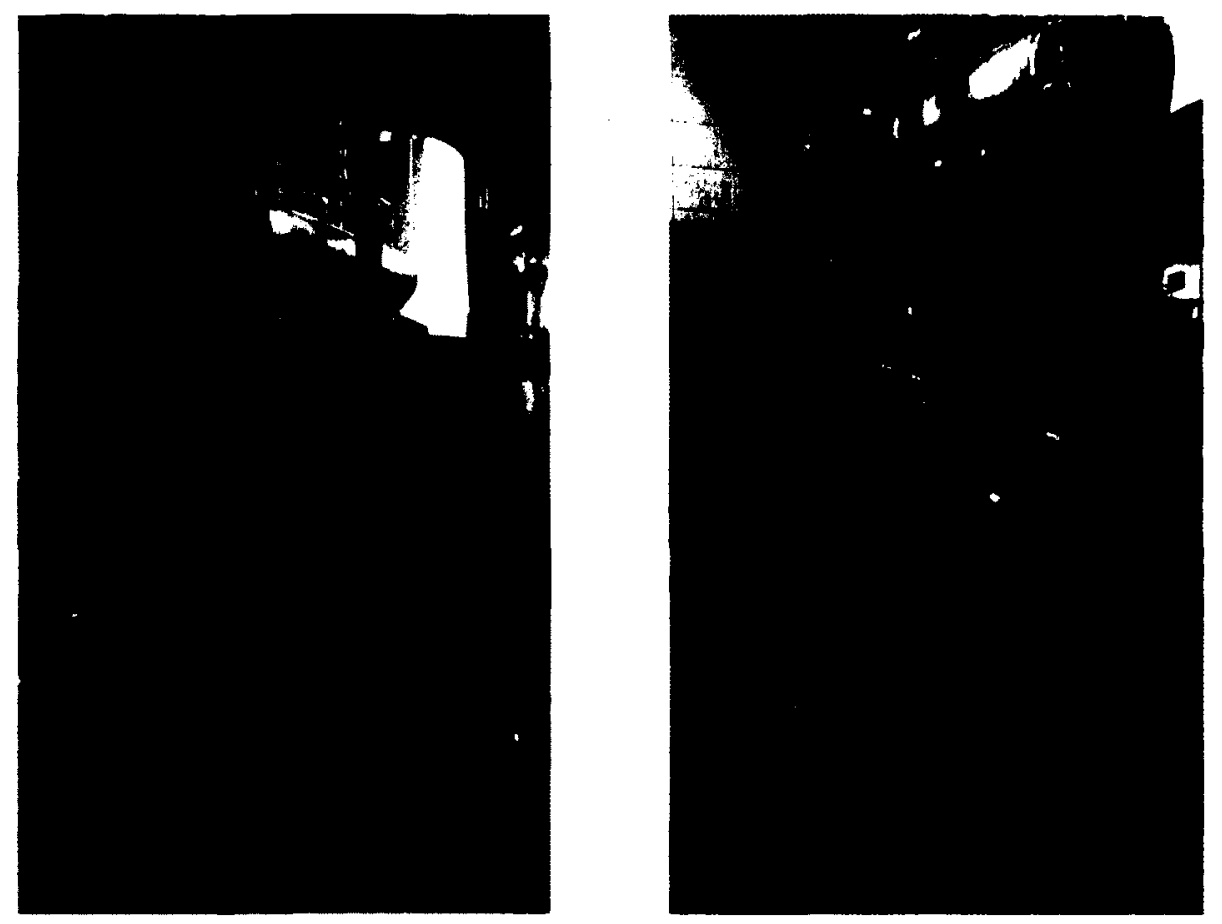

Figure 2.1: Hydraulic test bench

transfer paths shown in Figure 2.2. The specifications of the pumps used to circulate water between various components are listed in Table 2.1. Pumps 1 through 3 run at a single speed but their capacities can be varied over a limited range with the use of throttling valves. Heat transfer from one tank to the other can only be achieved by circulating flow directly between the two vessels. The valves were necessary to balance the flow rates between the two tanks in order to maintain a specific volume in each tank during experiments.

Table 2.1: Selected pumps

\begin{tabular}{ccc}
\hline Pump & Capacity (L/min) & Manufacturer/Model \\
\hline \hline Pump-1 & 36.6 & Grundfos/CR1-4 \\
Pump-2 & 36.6 & Grundfos/CR1-4 \\
Pump-3 & 36.6 & Grundfos/CR1-4 \\
Pump-4 & $3.8-36.6$ & Grundfos/CR1-3 \\
\hline
\end{tabular}


Thermal storage is provided by two $1300 \mathrm{~L}$ open cylindrical tanks having a maximum working temperature of $80^{\circ} \mathrm{C}$. A $10 \mathrm{~cm}$ thick layer of rigid glass fiber board strips laminated to an aluminum foil backing serves to insulate each tank. A flexible insulated, inflatable cover was built to further reduce heat losses and evaporation through the top of the tanks. Each tank was also fitted with 4 headers spaced radially at $90^{\circ}$ intervals. Each individual header allows for the addition or removal of fluid at 5 different points along the height of the tank. Figure 2.3 shows a schematic of the tank and header system. The vertical spacing between inlets is roughly $0.20 \mathrm{~m}$. The selection of inlet and outlet heights must be done manually using ball valves located between the tank and header outlet. The flexible top and header system allows the capacity of the tanks to be varied between experiments. The relative impact of inlet and outlet positions on thermal stratification can also be examined by varying their geometry between experimental runs.

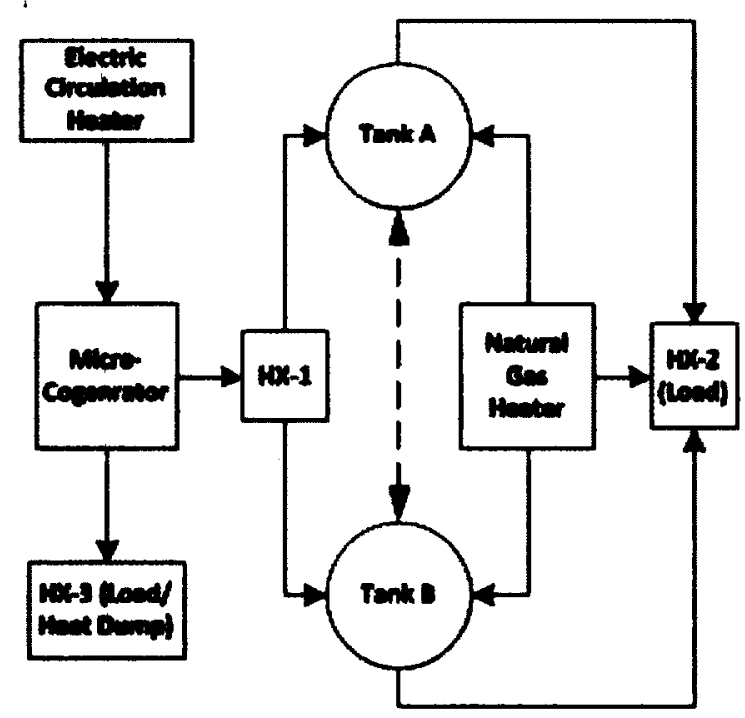

Figure 2.2: Plant heat transfer paths

Each tank has also been equipped with a thermocouple rack used to determine vertical temperature profiles during experiments. As many as 8 measurements can be taken along the centerline of the tank. Due to the size of the tanks and the position of the lowest outlet, a minimum volume of $100 \mathrm{~L}$ is required before fluid can be fed to the hydraulic test bench. Flexible hoses with a maximum working temperature of $100^{\circ} \mathrm{C}$ are used to connect the tanks to the hydraulic test bench. 


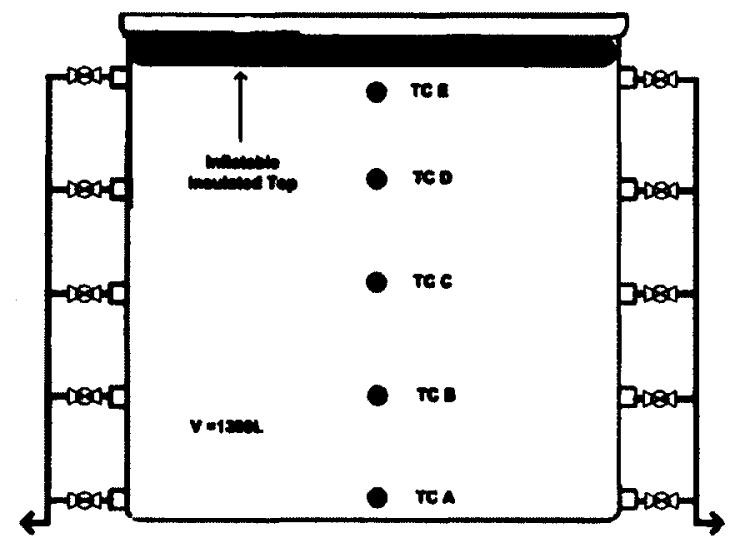

Figure 2.3: Tank and header system

Flat plate heat exhangers were selected for heat recovery from the microcogeneration unit to the thermal storage tanks and to dump heat from the tanks in order to simulate thermal loading. The specifications of the heat exchangers installed on the test bench can be found in Table 2.2. The capacities listed are those observed under typical operating conditions. Currently, water is used as both a heat

Table 2.2: Heat exchanger capacities

\begin{tabular}{ccl}
\hline Heat Exchanger & Capacity (kW) & Manufacturer/Model \\
\hline \hline HX-1 & 40 & SEC/M31B-50 \\
HX-2 & 20 & SEC/M11DC-50 \\
HX-3 & 30 & SEC/M31B-30 \\
\hline
\end{tabular}

transfer fluid and for thermal storage for the components located indoors where there is no risk of freezing. Heat can be transferred from the micro-cogeneration unit to either one of the thermal storages through a single flat plate heat exchanger (HX-1 in Figure 2.2). Direct coupling was avoided to allow the use of a glycol anti-freeze solution for heat recovery from units installed outdoors where the ambient temperature drops below freezing. The facility is currently being served by a dedicated chiller unit providing cooled glycol to the heat exchangers used for thermal loading at a temperature of $8^{\circ} \mathrm{C}$ and a flow rate of roughly $300 \mathrm{~L} / \mathrm{min}$. The heat transfer through the exchangers is limited by the capacity of the pumps chosen and the maximum operating temperature of a particular circuit.

The facility also includes two auxiliary heaters to supplement the thermal output 
from a micro-cogeneration device. A $20 \mathrm{~kW}$ in-line electric circulation heater was installed on the flow circuit servicing the cogeneration unit and can be controlled remotely to maintain a specific output temperature or its thermal output can be directly modulated. A $57 \mathrm{~kW}$ condensing tankless natural gas water heater can be placed in series with the thermal load to supplement the thermal output of the tank or micro-cogeneration device. The unit was also fitted with circuitry allowing the set-point temperature to be controlled remotely to a maximum temperature of $85^{\circ} \mathrm{C}$.

Controlled electrical loading of cogeneration units is possible using a programmable AC/DC load. The specifications of the load can be found in Table 2.3. The load has been integrated with the data acquisition and control system (DAQ) to subject units to user defined electrical load profiles realized at flexible time intervals. The load also comes equipped with on-board instrumentation to measure current,

Table 2.3: Electric load specifications

\begin{tabular}{ll}
\hline \hline Max. Load (W) & 4500 \\
Resolution (W) & 1.125 \\
Accuracy & $0.2 \%+0.3 \%$ F.S. \\
Voltage Range (V) & $50-350$ \\
Max. Current (A) & 45 \\
\hline
\end{tabular}

voltage and power. Measured or synthetic profiles can be developed to access the performance of electrically led systems or the load can be used to create electrical operating conditions such as steps and ramps needed to extract performance data for model calibration. The following section will treat issues relating to hardware integration, controls and data aquisition. 


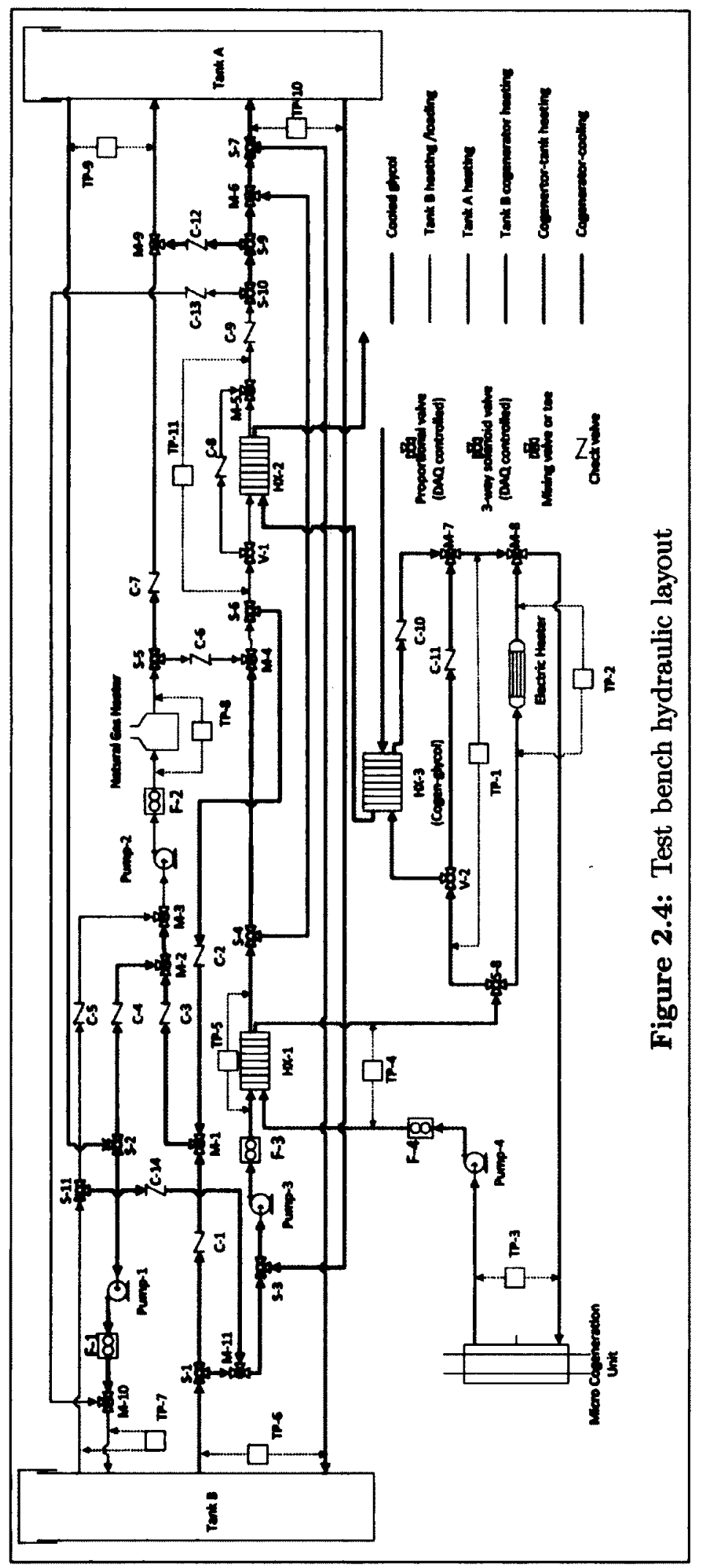




\subsection{Data Acquisition \& Controls}

The main objectives driving the design of the facility included the ability to easily switch between configurations, to run extended multi-day experiments autonomously, and to monitor and record measurements from a wide range of devices. To meet these objectives, a suitable platform was chosen to allow the centralized control and integration of all plant level components and data acquisition systems.

A real-time programmable automation controller built by National Instruments was selected as it provided the required processing power and flexibility needed to run the facility. The cFP-2220 controller was designed to accommodate a number of modules for both analogue and digital input/output, thermocouple measurement and measurement of pulse output devices. The controller comes with software that allows each individual channel of each module to be configured and monitored.

Using the highly flexible and well supported Labview programming environment, specific applications can be created to control components such as electronic valves, pumps, and embedded controllers such as those in the plant's auxiliary heaters. Once completed, applications can be deployed to the real-time controller in order to provide deterministic control of the hydraulic rig and measurement of system performance and process variables. Applications can also be run using a personal computer where connection to the DAQ is accomplished using an Ethernet cable. Although deterministic control is lost using this method, the technical support staff at National Instruments indicated that the delay associated with this method would be on the order of 100 ms which is small compared to the typical sampling intervals used for control and measurement of building systems.

Control of the 4 pumps and 11 solenoid driven 3-way valves on the test bench was achieved using a digital output module wired to a relay system capable of switching the electrical power to the devices. The 3-way valves come preconfigured with limit switches which remove power to the DC motor drive to provide accurate selection of the valve ports. Double-pole double-throw relay switches were necessary to allow bi-directional control of the valves. As only on/off control of the pumps was required, latching relays were chosen. Electrical diagrams showing the system layout and channel selection can be found in Appendix A.

Control of the two proportional valves (V-1 and V-2) on the test bench is achieved using a current signal ranging from $0-21 \mathrm{~mA}$ provided by the analogue output module. The valves have been configured to divert a portion of the flow around the heat 
exchangers used to simulate thermal loads. These valves are also fitted with switches limiting maximum and minimum possible by-pass fractions. The relative position of the valve between the chosen limits is proportional to the input signal provided. A closed loop proportional-integral-derivative (PID) control strategy was adopted based on either the temperature exiting the heat exchanger or the temperature difference across it. The control of each valve was tuned separately to provide the desired response. The ability to maintain a specific outlet temperature and the rate at which the thermal load can be varied are limited by the speed of the motorized valves.

The controller for the electric circulation heater comes equipped with a remote input allowing a current signal ranging between $4-21 \mathrm{~mA}$ provided by an analogue module to be used to modulate its output. The controller scales the input signal linearly to adjust the output temperature or the thermal power added to the flow. The set point temperature is maintained by the controller using a PID strategy. Improved performance can be achieved by tuning the controller around a particular set point. The internal thermocouple shipped with the unit was disabled and replaced with a calibrated Type $\mathrm{T}$ thermocouple placed directly at the heater outlet. The controller can accommodate an external thermocouple and allows a voltage offset to be used in order to better reflect the temperature voltage relationship of the calibrated sensor. Modulation of the thermal output is realized by varying the length of time the heater provides its maximum power over a given duty cycle. The length of the duty cycle can be manually adjusted from 5 to 60 seconds. The selection for either temperature or power control must also be configured manually.

The tankless natural gas heater was fitted with circuitry allowing its outlet temperature to be set using the DAQ. Under the typical mode of operation, the outlet temperature can be fixed by varying the position of a number of dip switches or by pushing the keys on a wired remote controller. In order to integrate the heater with the DAQ, reed relay switches were placed in parallel with the keys on the wired remote in order to simulate a human operator. A number of keys can be actuated using relays triggered by the digital output module. The unit can also be turned on or off remotely for the configurations where it is not physically possible to by-pass the heater but flow must run through it to dump heat to the load.

Remote control of the programmable electric load is possible through the RS-232 serial interface. A driver programmed in the Labview software is available but it only permits limited functionality. The driver is essentially a graphical user interface 
requiring a human operator to choose the desired load settings which are also controllable using the front panel of the device. It was assumed that the load would mainly be operated under a variable power mode where the primary parameter of interest was the magnitude of the power being drawn by the unit. In this mode of operation, the load senses the line voltage supplied and varies the amount of current being consumed to produce a specified load. Working under this assumption, an application was created allowing the power setting to be read from a file and set at a user-defined time interval. The on-board instrumentation can also be queried at flexible time steps and the results written to file with an appropriate time stamp. The application allows the load to be used more autonomously for multi-day experiments that would otherwise require a constant operator. Currently the load is connected to the host PC using a peripheral component interconnect (PCI) serial card. Running the hydraulic test bench controls and the electric load using the $\mathrm{PC}$ allows the synchronization of thermal and electrical loading and monitoring of system level performance.

The voltage signal created by the thermocouples and thermopiles embeded into the test bench (TP1-TP11 in Figure 2.4) is acquired using a number of thermocouple modules. The modules contain an internal thermistor used to measure the temperature of the junctions where the sensor leads are connected. The modules can be configured to provide software-based cold-junction compensation based on the curves developed by the National Institute of Standards and Technology (NIST) or the measured value can be used to implement a compensation method using calibration data.

The volumetric flow rate for both water and natural gas and electrical power are measured using pulse output devices. The oval gear flow meter placed on the line having the largest flow rate produces pulses having a frequency of approximately 60 $\mathrm{Hz}$. This measurement represents the largest pulse rate of all the instrumentation in the facility. The counter modules selected are capable of operating reliably at frequencies up to $50 \mathrm{kHz}$ allowing the instrumentation to be read with confidence. The modules also have $200 \mathrm{~Hz}$ and $50 \mathrm{kHz}$ low-pass filter settings to eliminate the effects from reed switch bouncing. The lower filter setting was sufficient for all measurements.

Finally, the current signal produced by the pressure transducer on the natural gas line is acquired and scaled using an analogue input module.

The following section will aim to describe some of the possible configurations suitable for characterising the performance of micro-cogenernation devices and complete micro-cogeneration systems. 


\subsection{Test Bench Configurations and Loading}

The testing facility can be broadly split into two sections each providing a different form of controlled loading. The first configuration allows the facility to create the controlled thermal and electrical operating loading required to generate data suitable for model calibration or performance mapping. This includes both steady-state loading at a number of fixed operating points and dynamic tests. The second portion of the facility was designed to explore suitable balance of plant configurations, control strategies and to provide realistic, controlled loading to micro-cogeneration systems. In this mode of operation, the facility has the ability to reproduce typical house space heating loads, domestic hot water demands, and electrical loading suitable to investigate the performance of units under realistic operating conditions.

The fluid circuit used to load the micro-cogeneration device was designed to operate independently from the remainder of the test bench. The line was fitted with a variable capacity pump to accommodate units of different sizes and to investigate the effect of flow rate on heat recovery. An inline electric circulation heater and a heat exchanger (HX-3 see Figure 2.4) with a controllable by-pass were built into the fluid circuit to modulate the return temperature to the micro-cogeneration unit. The DAQ-controlled proportional valve can be used to dynamically vary the fraction of the flow passing through the heat exchanger to produce a constant return temperature or to create time varying residential thermal loads to simulate performance of systems without thermal buffering. An upper limit of $40 \mathrm{~kW}$ can be removed from the flow stream exiting the cogeneration device. By varying the mass flow rate and fluid temperature through the micro-cogeneration unit, a complete performance map of thermal efficiency can be produced.

The hydraulic test bench is well-suited to studying the performance of both single and two tank systems. A large number of configurations are possible which are easily selected, controlled and monitored through the DAQ. Figure 2.5 shows the layout of a typical single tank system where heat can be recovered from a micro-cogeneration unit to be stored or sent directly to the residential load. The set-point of the tank can be maintained using either the cogeneration device or the natural gas heater. More flexible controls having two dead-bands allowing both heat sources to be used can also be implemented. Thermal loading is provided through another heat exchanger using the same strategy employed on the loop servicing the micro-cogeneration unit. 


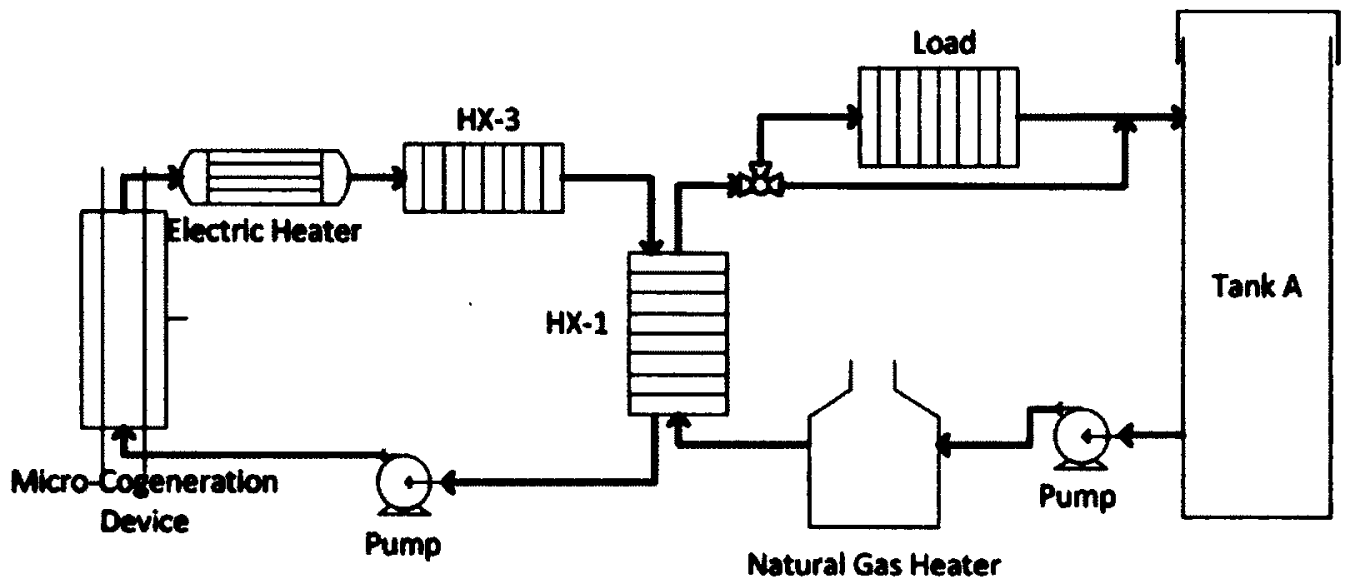

Figure 2.5: Single tank system

The output of the electric circulation heater can also be varied under a one-minute duty cycle in order to simulate the thermal output of a cogeneration device or a secondary heat source such as a solar thermal system. In the case where units are run continuously or are electrically led, excess heat can be dumped through HX-3 to prevent overheating. Continuous monitoring of flow rates and temperatures allows heat balances to be determined across each component.

A number of two-tank configurations are also possible allowing the thermal storages to be charged or discharged in series or in parallel. Figure 2.6 shows the series arrangement where one tank is used as a buffer for a second tank serving the residential loads. In the case where the tanks are used in parallel, different set points can be

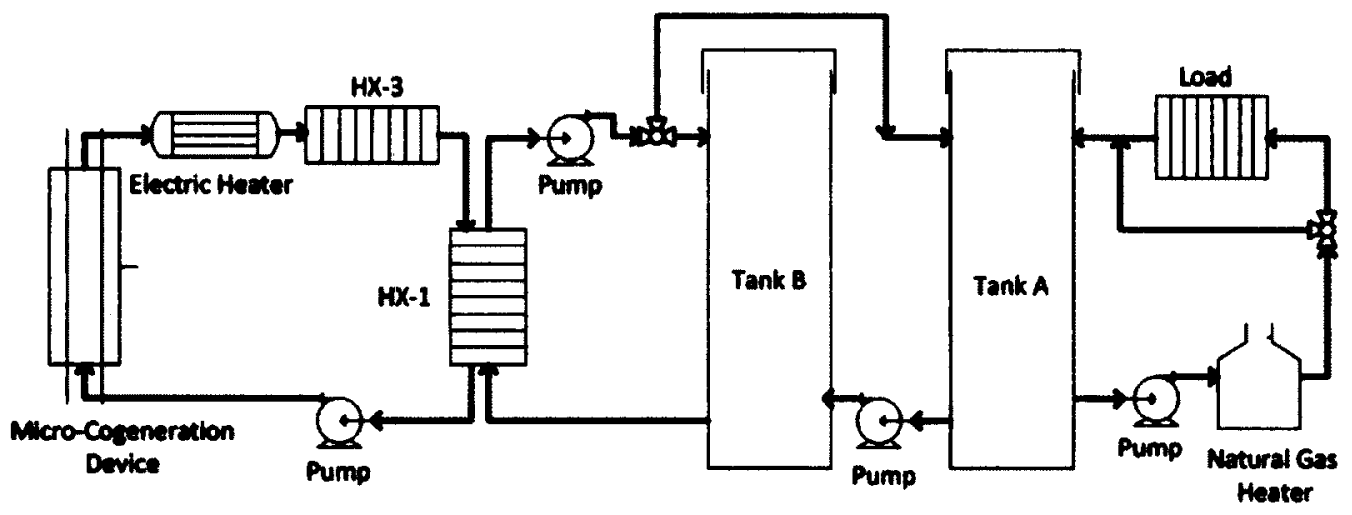

Figure 2.6: Two-tank series system

maintained for separate domestic hot water production and for space heating. In the configuration shown below in Figure 2.7, Tank B can be charged by the cogeneration unit and can dump heat to the load. Tank A can be charged by both the cogeneration 
device and by the natural gas heater and can also dump heat to the load. A number of other configurations are also possible by making the appropriate valve selections. The test bench essentially provides an independent path between the tanks, individual circuits connecting each tank to the micro-cogeneration heat exchanger, the natural gas heater, and the thermal load. Custom controls can be created to manage the buffering system and auxiliary heat sources. User defined load profiles generated

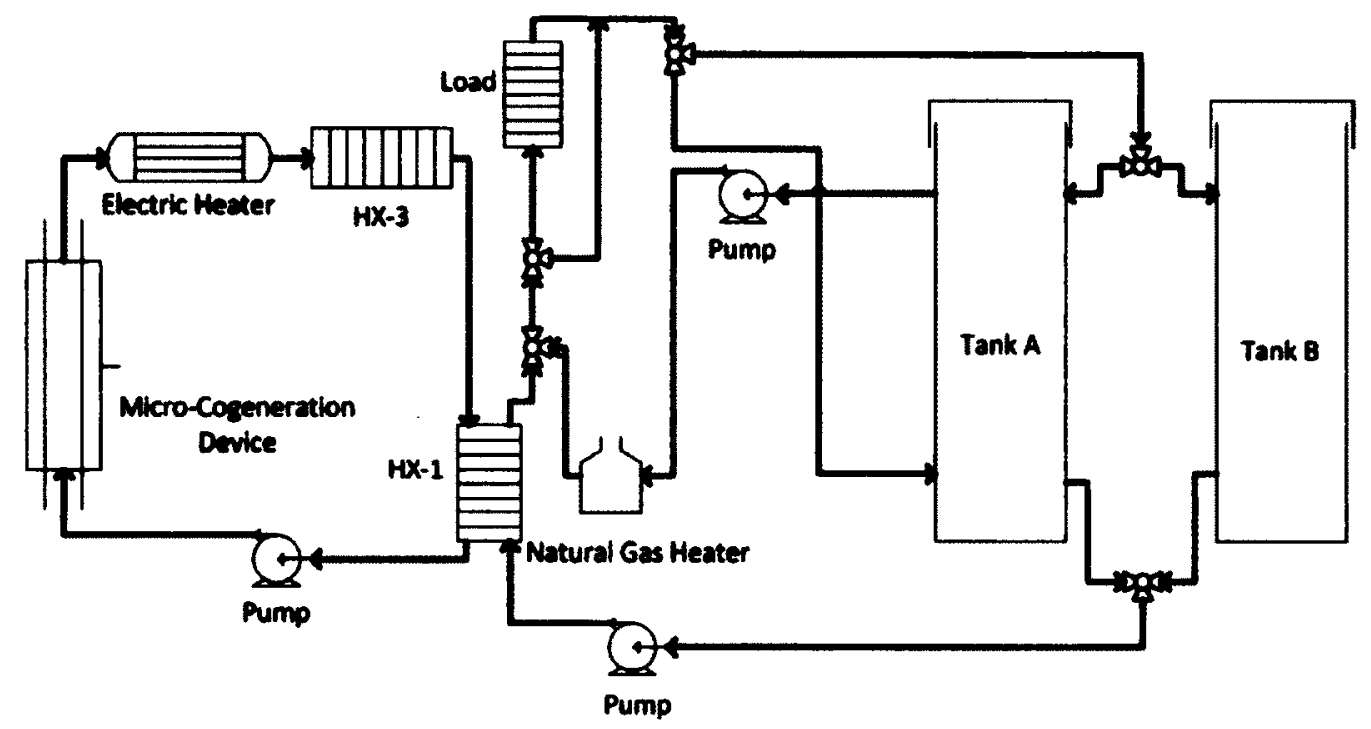

Figure 2.7: Two-tank parrallel system

from building simulations and actual measurements can be reproduced using time intervals as little as 5 minutes. Representative profiles for typical days throughout the year can be created and reproduced to assess seasonal performance of units. The test bench can be used to explore and evaluate charging and discharging strategies to determine how best to control the units to minimize cycling or stand-by losses. Experiments ranging in length from several hours to several weeks are possible and can be run almost autonomously.

Figure 2.8 shows the electrical line diagram for the proposed installation of a 6 $\mathrm{kW}_{e}$ micro-cogeneration unit. As the electrical output of the device is larger than the capacity of the load, three electric base-board heaters were added to allow the device's complete range to be tested. The unit chosen for this installation can be controlled in a number of ways but a grid connection must be established before the unit is operable. 


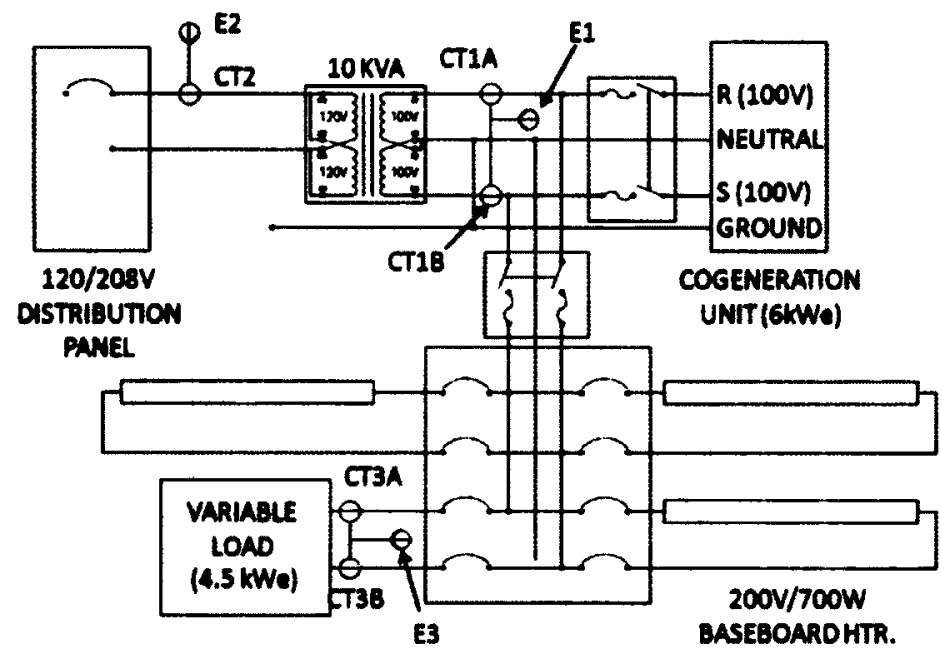

Figure 2.8: Electrical line diagram

The output from the inverter provides power suitable for $200 \mathrm{~V}$ split-phase systems which are common in Japan. In order to integrate the unit with the facility's electrical service, a voltage transformer was placed between the loads and the distribution panel. Electrical load following is realized using directionally sensitive current transducers. The unit can modulate its output to maintain a maximum power export of roughly $200 \mathrm{~W}$. It can also be heat led using either a thermostat with a relay switch or the unit can operate using a timer. Under heat led control, the unit can only run at maximum capacity. The load bank can be disconnected when the unit is operating using a heat led strategy allowing the electricity produced to be used to power equipment in the facility and the adjacent lab space. Additional power produced is exported in the remainder of the building.

The facility can be used to drive micro-cogeneration units using realistic thermal and electrical load profiles reproduced at variable time steps. The flexibility of the hydraulic test bench and user defined control allows an almost unlimited number of configurations to be explored and evaluated. In order to take advantage of the flexibility of the facility, a significant amount of instrumentation has been embedded into the hydraulic test bench. The following chapter will describe the instrumentation selected, its calibration and the resulting measurement accuracy. 


\section{Chapter 3}

\section{Instrumentation and Sensor Calibration}

This chapter provides a description of the instrumentation embedded into the hydraulic test bench to measure thermal power, the instrumentation employed to measure natural gas properties, and the metering system for the proposed electrical installation of a $6 \mathrm{~kW}$ micro-cogeneration device. The specifications and justification of each sensor will be explained. A detailed description of the thermocouples and thermopiles installed on the test bench is also provided. Details relating to their construction, assembly, calibration and resulting measurement uncertainty will be addressed.

\subsection{Instrumentation}

In order to take advantage of the flexibility of the hydraulic test bench, a large amount of instrumentation was added at critical locations. Positive displacement oval gear flow meters were selected to measure the flow rate through each of the pumps. The meters are factory calibrated to produce a train of pulses proportional to the measured flow rate. The meters were flexible enough to cover the range of flow rates expected and their rotors have an upper operating temperature limit of $80^{\circ} \mathrm{C}$ which was consistent with other components on the test bench. An estimate of the flow can be obtained by reading the number of pulses registered over a given sampling interval. The specifications of each meter can be found in Table 3.1.

The natural gas line used to fuel the instantaneous water heater and cogeneration unit has been instrumented to measure temperature, pressure and volumetric flow. The gas temperature is measured upstream of each flow meter using calibrated 
Table 3.1: Flow meter specifications

\begin{tabular}{ccccc}
\hline Flow Meter & $\begin{array}{c}\text { FlowRate } \\
\text { (L/min) }\end{array}$ & $\begin{array}{c}\text { Pulse Rate } \\
\text { (Pulse/L) }\end{array}$ & Accuracy & Model \\
\hline \hline F-1 & $3-25$ & 112 & $1 \%$ of reading & Brooks /BM-04 \\
F-2 & $3-25$ & 112 & $1 \%$ of reading & Brooks /BM-04 \\
F-3 & $8-70$ & 52 & $1 \%$ of reading & Brooks /BM-07 \\
F-4 & $3-25$ & 112 & $1 \%$ of reading & Brooks /BM-04 \\
\hline
\end{tabular}

thermocouples inserted into wells which are directly exposed to the flow. Natural gas pressure is monitored at the inlet of the facility with an accuracy of $0.25 \%$ of reading. The volumetric flow to the water heater and cogeneration device are measured separately using revenue grade diaphragm meters. Table 3.2 describes the meters chosen. Under typical operating conditions, the warranted accuracy for this type of meter is $1 \%$ of reading. The primary dial on the meter travels one full rotation per $0.0283 \mathrm{~m}^{3}$ of flow through the meter. In order to measure the gas flow with the DAQ, a rotary encoder with a pulse rate of 1000 pulses per revolution was mounted to the dial of the meter. The combination of the dry test meter and encoder provides excellent

Table 3.2: Natural gas meter specifications

\begin{tabular}{ccc}
\hline FlowRate(L/min) & Accuracy & Manufacturer/Model \\
\hline \hline 95 & $1 \%$ of reading & Elster / DTM 200-A \\
\hline
\end{tabular}

resolution of natural gas volumetric flow. Estimates of the molar flow rate of natural gas can be derived using the measured temperature, pressure, and flow rates observed on the line. An estimate of the heating value of the fuel is needed to compute the molar heat rate into a particular device.

A third branch was included on the line to accommodate more equipment such as a gas chromatograph or to allow gas samples to be taken for laboratory analysis to determine heating value of the fuel. Figure 3.1 shows the layout of the natural gas line and instrumentation. Currently, the natural gas supply to the building services the testing facility exclusively and is independently metered by a third meter installed outdoors. The volume of gas consumed by both the heater and the cogeneration 


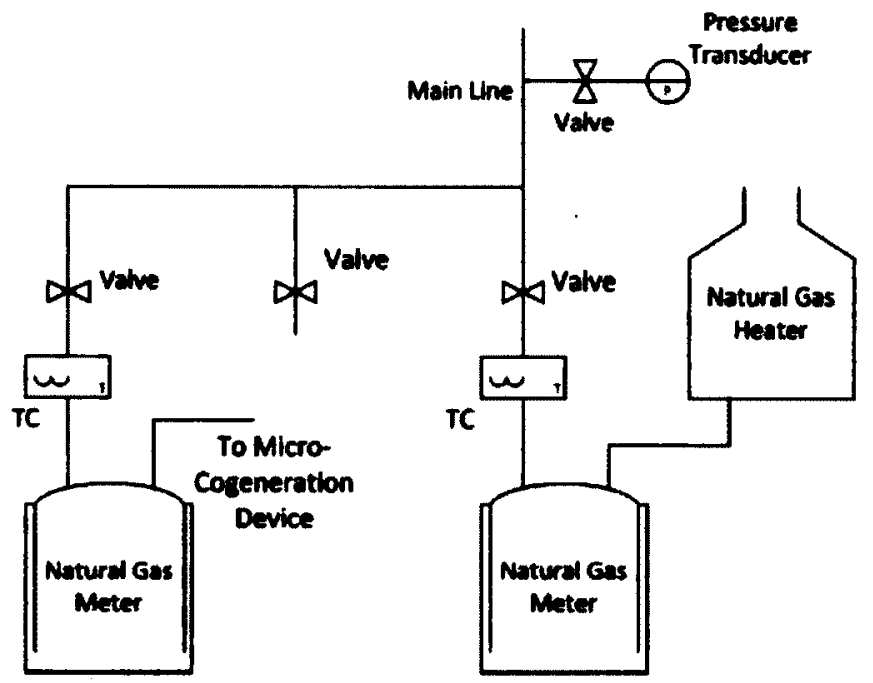

Figure 3.1: Natural gas system

device over a testing period can be compared to that recorded by the third meter in order to provide some measurement redundancy.

Electrical power was assumed to be measured using bi-directional revenue grade energy meters having a pulse output and split core current transducers. The energy meters can be configured to produce a separate pulse train proportional to the power measured in both directions. Figure 3.2 shows the layout of the proposed electrical measurement system. The flow of electrical power can be measured across 3 locations providing an assessment of transformer losses, electricity imported and exported, and power consumed by the loads. The losses across the transformer can be measured by taking the difference between $\mathrm{E} 1$ and $\mathrm{E} 2$ while the power consumed by the programmable load and the heaters can be resolved between points E1 and E3. The choice of bi-directional meters also allows an assessment of the unit's load following capabilities by measuring the amount of power exported/imported to the distribution panel during periods of controlled variable loading.

The specifications for the energy meters and the current transducers can be found in Tables 3.3 and 3.4. The energy meters require current transducers having an output ranging from $0-0.333 \mathrm{VAC}$ which is proportional to the instantaneous line current. Most commercially available current transducers typically have a leading phase angle error ranging from 0.2 degrees to 2.5 degrees. The energy meters are normally programmed to correct for a 1.0 degree phase lead to improve accuracy. They can be configured to sense the voltage between the live and neutral phases or 


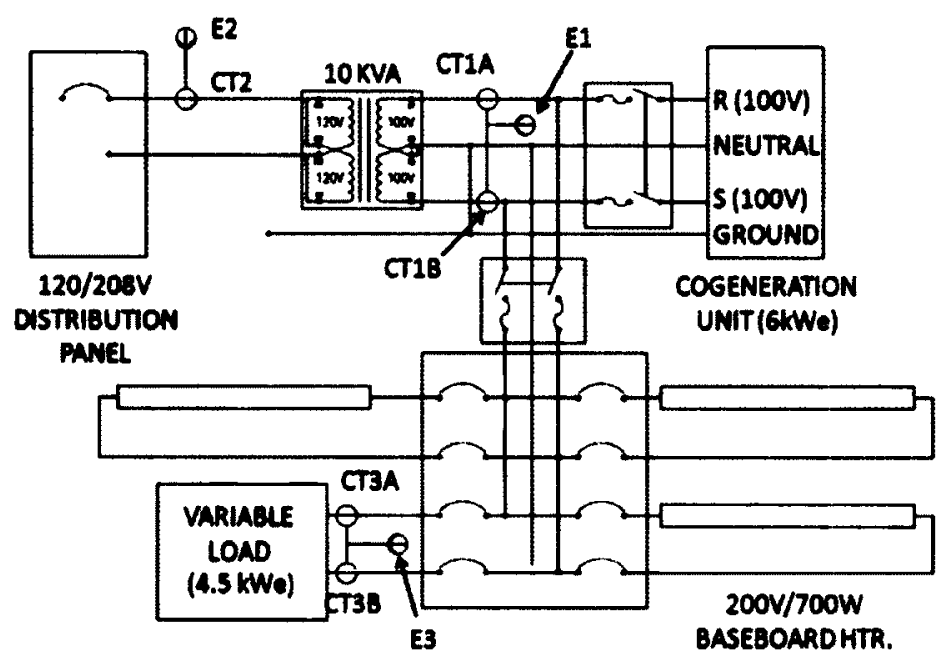

Figure 3.2: Electrical power measurement system

the two live phases in a split phase system using voltage taps. The meters integrate the instantaneous current and voltage to produce a pulse train having a frequency of 4 $\mathrm{Hz}$ at their maximum power rating. Although models capable of producing pulses at a rate of up to $600 \mathrm{~Hz}$ were available, the chosen meters provide adequate resolution given the capacity of the micro-cogeneration unit and the likely measuring interval. The meters draw power directly from the voltage taps for internal consumption, but the power used is on the order of $10 \mathrm{~mW}$ which is negligible compared to the power being measured.

Table 3.3: Energy meter specifications

\begin{tabular}{ll}
\hline \hline Manufacturer & WattNode \\
Model & WNB-3Y-208-P 120 \\
Nominal line voltage & 120 \\
Frequency & $48-62 \mathrm{~Hz}$ \\
Ouput (pulse/kWh) & 1333.33 \\
Accuracy & $0.5 \%$ of reading \\
\hline
\end{tabular}

Based on the maximum electrical power of the generating unit, $30 \mathrm{~A}$ current transducers were selected to measure each of the live phases from the generator and the 
power drawn by the load. A $70 \mathrm{~A}$ transducer was selected for measuring power exported to the distribution panel. Proper sizing of the transducers was important to ensure the energy meters operate at their highest point of accuracy. Additional measurement error must be included for off-design conditions including high/low current or low power factors. The electric load can be configured to have a power factor of unity, while the baseboard system results in purely resistive loading providing better accuracy of measured energy. Custom split core units were chosen to further reduce the bias on the current measurement. The quoted linearity error for the selected transducers is warranted between $10 \%-130 \%$ of rated current, and the phase shift introduced was measured at $50 \%$ of the rated capacity ( 15 or $35 \mathrm{~A}$ ). The custom designed split core transducers offer a similar accuracy as the solid core sensors but can be installed or reconfigured after the initial electrical installation. The split core system provides a good compromise between cost, accuracy and flexibility.

Table 3.4: Current transducer specifications

\begin{tabular}{ll}
\hline \hline Manufacturer & Magnelab \\
Type & Split core \\
Rated current (A) & $30 / 70$ \\
Linearity error (\%) & 0.2 \\
Phase error (\%) & $\leq 1$ \\
\hline
\end{tabular}

The programmable load also comes equipped with internal instrumentation to measure current, voltage and power. The DAQ can query the device at user defined intervals in order to generate an independent data set to compare with the instrumentation previously described. The specifications of the on-board instrumentation are listed in Table 3.5 .

A large number of thermocouples and thermopiles have been embedded into the hydraulic test bench and storage tanks to measure both single point temperatures and temperature differences between locations. Both thermocouples and thermopiles were calibrated over the entire operating range of the test bench in order to reduce measurement uncertainty. Table 3.6 shows the total uncertainty for a temperature 
Table 3.5: Programmable load instrumentation

\begin{tabular}{cccc}
\hline Parameter & Range & Resolution & Accuracy \\
\hline \hline Voltage & $0-500 \mathrm{~V}$ & $10 \mathrm{mV}$ & $0.1 \%+0.1 \%$ F.S. \\
Current & $0-200 \mathrm{~A}$ & $2.5 \mathrm{~mA}$ & $0.1 \%+0.2 \%$ F.S. \\
Power & $0-4500 \mathrm{~W}$ & $1.125 \mathrm{~W}$ & $0.2 \%+0.3 \%$ F.S. \\
\hline
\end{tabular}

measurement including error sources from both calibration and experimental measurement. This includes sources such as voltage reading errors, reference temperature bias, cold-junction compensation and calibration uncertainty. A detailed treatment of the calibration process and the resulting uncertainty will be provided in the following section. In order to evaluate the heat transfer between or across components, an esti-

Table 3.6: Temperature sensors specifications

\begin{tabular}{lll}
\hline Temperature Sensor & Manufacturer & Accuracy $\left({ }^{\circ} \mathrm{C}\right)$ \\
\hline \hline Type T Thermocouple & Omega & 0.5 \\
5-junction Thermopile & Built In-house & 0.1 \\
\hline
\end{tabular}

mate of the fluid flow rate and temperature change must be made. Compound sensors comprised of a single 5-junction thermopile and 2 thermocouples were placed across the inlets and outlets of each heat exchanger, both auxiliary heaters and the headers of each tank. The location of the sensors can be found in Figure 2.4 and are labelled TP-1 through TP-11. Only the hot side of HX-1 and HX-2 were instrumented as only the heat loss from the warm flow is needed. The temperature difference across a component can be read from the two independent thermocouple readings or directly from the output from the thermopile.

It should be noted that the temperature reading using the thermocouples is software compensated and measures the temperature either at the inlet or the outlet of a component. Thermopiles are a temperature difference sensor by definition whose output (emf) is proportional to the difference between the hot and cold-junctions embedded across a particular component. The structure chosen allows for the duplication of temperature measurement to improve confidence and to troubleshoot sensors. The 5-junction thermopile is constructed by creating 5 thermocouple junctions on both 
the supply and return sides of a component. The thermocouple junctions are wired in series to produce a thermopile producing a voltage approximately 5 times as large as that of a single thermocouple wired across the same temperature difference. Figure 3.3 is a schematic of the compound sensors embedded into the test bench while Figure 3.4 illustrates their actual construction. Each half of the sensor is comprised

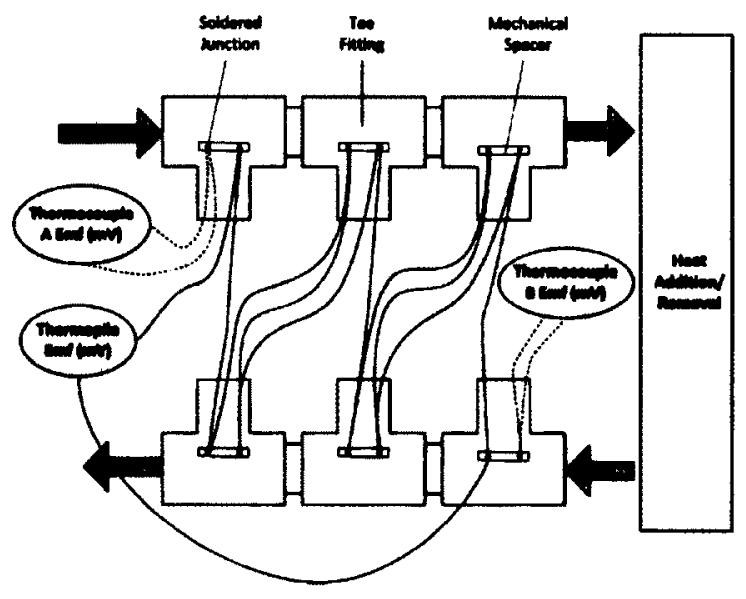

Figure 3.3: Compound sensor schematic

of 3 brass Tee-fittings containing a total of 6 soldered thermocouple junctions. The first 5 taken together form either the hot or cold junction of the thermopile while the last one is simply used as a thermocouple. Four holes were drilled into the threaded plugs of each tee-fitting to accommodate the wires forming the soldered junctions. The length of the wires was chosen such that the soldered junctions were directly immersed in the mid-pane of the flow through the sensor.

A water-proof, electrically isolative steel epoxy was used to seal the wire/plug assembly. Plastic mechanical spacers were added to prevent the two junctions from coming into contact with each other or the inner surface of the fitting. A small amount of epoxy was also placed at the end of the wire sheath before the exposed wire to prevent water from seeping out of the sensor. The modular construction of the compound sensors allows the pairs of junctions to be tested or repaired without the need to completely remove the sensor.

The following section will describe the experiments performed to calibrate the thermocouples and 5-junction thermopiles. It will also explain and identify the various sources of error that contribute to the total temperature bias error for each sensor. 


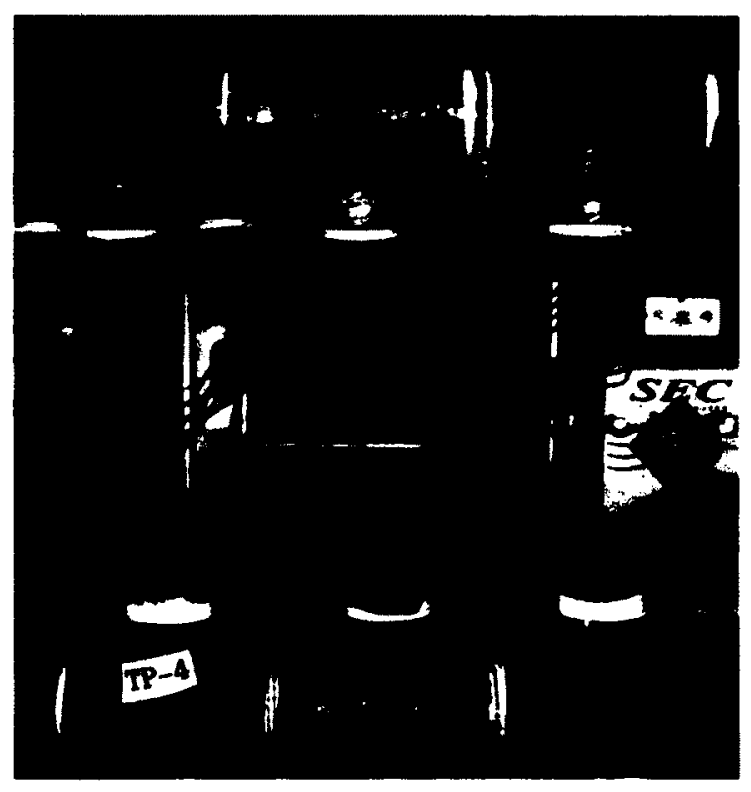

Figure 3.4: Temperature sensor assembly

\subsection{Thermocouple Calibration and Uncertainty}

As previously mentioned, a calibration experiment was undertaken to reduce the uncertainty associated with temperature and temperature difference measurements. Rather than implementing the coefficients from the NIST used in typical thermocouple measurements, a unique calibration data set relating the thermocouple output voltage to a temperature was experimentally derived. The calibration data was generated by immersing the measuring junction of the thermocouple into a constant temperature bath and logging the emf ( $\mathrm{mV}$ signal) produced. The cold-junction temperature was recorded using a thermistor built into the DAQ while the measuring junction temperature was recorded using a platinum resistance thermometer with a resolution of $0.020^{\circ} \mathrm{C}$. Calibration data expressing the platinum probe's resistance as a function of temperature provided by the manufacture was fit to a second order polynomial found below. The error resulting from the regressions was small enough that it could be neglected as it was an order of magnitude smaller than that of the thermometer reading the resistance.

$$
T\left({ }^{\circ} \mathrm{C}\right)=0.001 R^{2}+2.309 R-240.843
$$


Measurements of both voltage and temperature were recorded at roughly $5^{\circ} \mathrm{C}$ intervals between $2-85^{\circ} \mathrm{C}$. The temperature of the bath was allowed to reach a state of equilibrium before the measurements were taken. In order to eliminate the precision error from the calibration, measurements were recorded every second over a period of 4 minutes and a data point was repeated if the standard deviation of the bath temperature was larger than a fraction of a percent of the mean value. An ordered pair was created by averaging the emf and temperature measured over the logging period. A second order polynomial was also fitted to this data set.

The calibration procedure employed assumes that the voltage-temperature relationship of the test thermocouple is representative of the entire $100 \mathrm{~m}$ spool of wire used to build the sensors. Initially, a single spool was used for the construction of all thermocouples and thermopiles; however, more wire was required to complete the instrumentation. A second spool of Omega type $T$ wire having the special limits of error (SLE) tolerance was purchased and was also calibrated. The instrumentation directly embedded in the hydraulic test bench was built using the first spool $\left(T C_{B L}\right)$ while the instrumentation in the tanks, heaters and natural gas lines used the second spool $\left(T C_{B R}\right)$. Table 3.7 shows the polynomial fits obtained for each wire spool and the maximum regression error resulting from their use. The regression error accounts for maximum difference between a temperature-voltage ordered pair from the calibration experiment and the values predicted by the curve fit used to represent the data. The temperature response of both spools over the range of interest is very similar indicating a good consistency of wire composition between production batches. The

Table 3.7: Thermocouple regression equations

\begin{tabular}{ccc}
\hline Thermocouple & Regression Equation & Regression Error $\left({ }^{\circ} \mathrm{C}\right)$ \\
\hline \hline$T C_{B L}$ & $T\left({ }^{\circ} \mathrm{C}\right)=-0.5194 \mathrm{emf}^{2}+24.683 e m f+21.159$ & 0.157 \\
$T C_{B R}$ & $T\left({ }^{\circ} \mathrm{C}\right)=-0.5231 \mathrm{emf}^{2}+24.748 \mathrm{emf}+21.159$ & 0.230 \\
\hline
\end{tabular}

error resulting from interpolation within the data set is significantly smaller than that from the generic curves because the temperature range considered is relatively small and only the bias errors of the calibration system contributed to the total error. The correlations developed were used to convert the output voltage to a temperature and to implement a software compensation to account for the cold-junction temperature. 
The data used to calibrate both thermocouple wires can be found in Appendix B.

The individual bias sources contributing to the total measurement uncertainty can be found in Table 3.8. The total bias was calculated by taking the summation of the root mean square of each bias source. All bias sources identified were taken as being independent. The largest source of error results from the thermistor used to determine the cold-junction temperature. The manufacturer of the DAQ system warrants a resolution of $0.250^{\circ} \mathrm{C}$ for the thermistor and recommends an additional bias of $0.200^{\circ} \mathrm{C}$ to account for its location within the module rather than directly on the cold junction.

A reference junction error was introduced during the calibration because an average cold-junction temperature was used to develop the curve fit while this value actually varied throughout the calibration experiment. The temperature recorded by the thermistor varies with the ambient temperature of room. The average temperature over the entire calibration experiment was taken as the point around which the software compensation was based. The value presented in the table is the maximum difference between the average cold-junction temperature of an ordered pair and the average over the entire experiment. This observation is significant as this parameter introduces a bias source into the calibrations which could not be controlled directly. The calibration was repeated a number of times in order to reduce this error as room temperature fluctuations over a 4-hour period can vary much more than the total uncertainty desired for thermocouple.

The second largest source of bias results from the regression prediction error used to account for the maximum possible variation between the calibration data and the polynomial fit used to represent the data set. The resolution of the instrumentation used to read the thermocouple voltage also contributed strongly to the total bias. The manufacturer of the modules used to measure thermocouple voltages reported a bias of $0.008 \mathrm{mV}$. This source of bias occurs during both the calibration procedure and during experimental measurements.

A sensitivity parameter was required to propagate the voltage reading bias into a temperature measurement bias. The sensitivity factor was calculated by taking the derivative of the regression equations with respect to emf for both curve fits. The maximum voltage produced over the calibration was $2.938 \mathrm{mV}$ yielding a sensitivity factor of $21.55^{\circ} \mathrm{C} / \mathrm{mV}$. The product of the voltage error and its sensitivity factor results in a temperature bias of approximately $0.200^{\circ} \mathrm{C}$. A more detailed treatment 
Table 3.8: Thermocouple bias sources

\begin{tabular}{lc}
\hline Bias Source & $\operatorname{Bias~}\left({ }^{\circ} \mathrm{C}\right)$ \\
\hline \hline Reference junction & 0.130 \\
Voltage read error (experiment) & 0.200 \\
Platinum RTD & 0.020 \\
Thermistor & 0.250 \\
Thermistor location & 0.200 \\
Regression prediction error & 0.230 \\
Voltage read error (calibration) & 0.200 \\
\hline Total Bias & 0.500 \\
\hline
\end{tabular}

of sensitivity factors and the propagation of measurement errors can be found in Chapter 4. Finally, the bias of the platinum probe used to measure the calibration bath temperature was included to complete the overall measurement uncertainty.

\subsection{Thermopile Calibration and Uncertainty}

A similar calibration exercise was conducted to calibrate the 5-junction thermopiles. The cold and hot-junctions were placed in two separate baths to create a known temperature difference across the thermopile and the voltage produced was measured directly using the DAQ system. The bath temperatures were simultaneously measured and logged using two platinum resistance thermometers. All data were logged at one second intervals for a period of 4 minutes under steady state conditions. The calibration data for the second platinum probe was also fitted to a polynomial (shown below) producing a negligible error.

$$
T\left({ }^{\circ} \mathrm{C}\right)=0.001 R^{2}+2.300 R-240.863
$$

Because the output of the thermopile is sensitive to both the hot and cold-junction temperatures, both of these parameters were systematically varied to produce a calibration map relating an output voltage to a temperature difference. For a given 
cold-junction temperature, a data set of voltages was created by increasing the hotjunction temperature in increments of $5^{\circ} \mathrm{C}$ until the upper temperature of the test bench was reached. This procedure was repeated for a large range of cold-junction

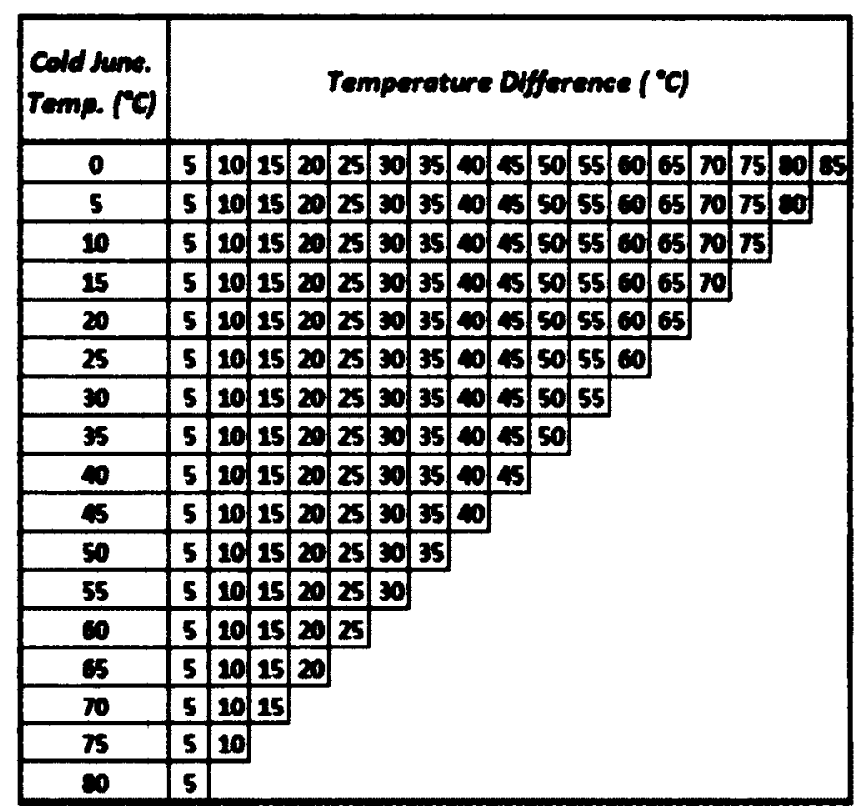

Figure 3.5: Thermopile calibration map

temperatures to characterise the thermopile response. Figure 3.5 shows the matrix chosen to calibrate the thermopiles. Multivariate regression was used to express the hot-junction temperature as a function of cold-junction temperature and emf produced. A large number of functional forms were explored, but a 10-coefficient cubic was ultimately chosen as it provided the best representation of the data. Rather than taking a least squares approach, the fitting target chosen aimed to minimize the maximum value of the absolute error between the calibration data and the curve fit. It was important to reduce this source of error as much as possible because the largest regression error within the calibration data set is chosen to provide the confidence interval for the temperature measurement. This particular source proved to be the largest contributor to the overall uncertainty of the measurement. The coefficients resulting from the regression can be found in Table 3.9. The maximum error introduced by the regression equation was calculated to be $0.087^{\circ} \mathrm{C}$ while the average error was approximately $0.003^{\circ} \mathrm{C}$. A sample of the data used to calibrate the thermopiles can 
Table 3.9: Thermopile regression coefficients

\begin{tabular}{cc}
\hline Coefficient & Value \\
\hline \hline $\mathrm{a}$ & $-6.9185613467257445 \mathrm{E}-01$ \\
$\mathrm{~b}$ & $5.1683542486939711 \mathrm{E}+00$ \\
$\mathrm{c}$ & $9.8133216067597717 \mathrm{E}-01$ \\
$\mathrm{~d}$ & $2.7883637404332424 \mathrm{E}-02$ \\
$\mathrm{f}$ & $2.2893880402369271 \mathrm{E}-04$ \\
$\mathrm{~g}$ & $2.3694605271328006 \mathrm{E}-04$ \\
$\mathrm{~h}$ & $-6.7512031136812368 \mathrm{E}-07$ \\
$\mathrm{i}$ & $-1.1230683426105850 \mathrm{E}-02$ \\
j & $1.7460387464790389 \mathrm{E}-04$ \\
k & $2.2951552440429009 \mathrm{E}-05$ \\
\hline
\end{tabular}

be found in Appendix $\mathrm{C}$ along with a summary of the errors resulting from the polynomial curve fit. The complete data set can be found online on a repository hosted by the Carleton University Faculty of Mechanical and Aerospace Engineering [22].

$T_{H J}=a+b e m f+c T_{C J}+d e m f^{2}+f T_{C J}^{2}+g e m f^{3}+h T_{C J}^{3}+i e m f T_{C J}+j e m f^{2} T_{C J}+k e m f T_{C J}^{2}$

As with the thermocouples, a total bias error was obtained by taking the summation of the root mean square of each individual bias source. The sources contributing to the total bias of the thermopile measurement can be found in Table 3.10. The regression prediction error contributed the largest fraction of the uncertainty followed by the read error from the voltage measurements occurring during both the calibration and experiment. Although the use of the thermopiles requires that the cold-junction temperature be measured using a thermocouple, the bias from this measurement need not be included in the uncertainty for the temperature difference measurement. This can be attributed to the fact that the relationship between the emf produced and the temperature difference is nearly linear and that this slope remains virtually constant over such a small change in the cold-junction temperature. Figure 3.6 showing the 
predicted hot-junction temperature as a function of the cold-junction temperature and emf produced clearly illustrates this result. By taking the first derivative of the regression equation with respect to emf, a sensitivity parameter was obtained which could be used to propagate the error from the voltage measurement into the temperature measurement. The sensitivity factor was calculated to be $4.5954^{\circ} \mathrm{C} / \mathrm{mV}$. The product of this value and the voltage read error results in a bias of $0.036^{\circ} \mathrm{C}$.

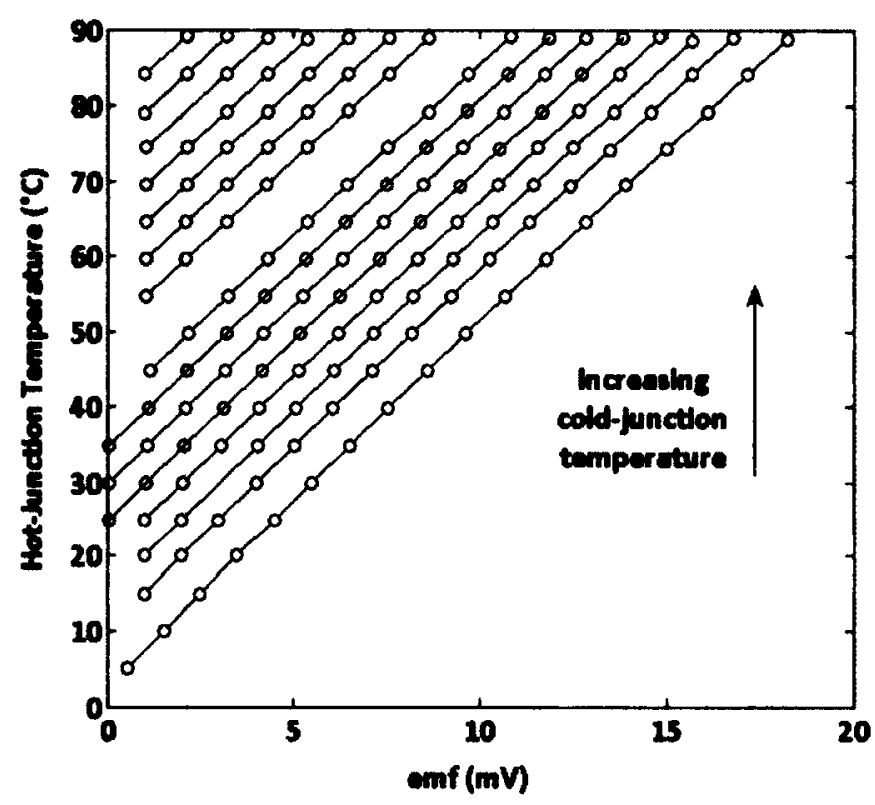

Figure 3.6: Hot-junction temperatures

In order to make the connection with the DAQ, copper/nickel extension wires were used. The construction of the thermopiles from Type $T$ thermocouple allows both lead wires leaving the sensor to be made from copper. The composition of the extension wires was different from that of the leads from the sensor which acts to produce another set of junctions. If the junctions were at different temperatures during an experiment, this would act to reduce or increase the emf measured by the DAQ. To assess the impact of the new junctions, another five-junction thermopile was built this time using only the copper thermocouple wire and the wire selected for the extensions to the DAQ. The new thermopile was placed in the calibration baths to create a $50^{\circ} \mathrm{C}$ temperature difference and the resulting emf was logged. The fivejunction thermopile was chosen to amplify the potential error produced (by a factor of 5) and the temperature difference was chosen to be much larger than would be 
observed in the lab during an experiment. Even under these exaggerated conditions, the emf produced could not be resolved by the thermocouple module indicating that the extension wires would not affect the measurement accuracy.

It is notable that the uncertainty for a temperature measurement difference made by taking the difference between two thermocouple measurements is 7 times greater than that of the calibrated thermopile. The difference between these methods can be attributed to two main factors. Firstly, once calibrated, the output voltage from the thermopile can be read without any need for cold- junction compensation. Secondly, the increase in signal strength greatly reduces the relative error attributed to the resolution limit on the hardware used to read the emf produced. The total uncertainty and the sources contributing to this error are listed in Table 3.10.

Table 3.10: Thermopile bias sources

\begin{tabular}{lc}
\hline Bias Source & Bias $\left({ }^{\circ} \mathrm{C}\right)$ \\
\hline \hline Voltage read error (calibration) & 0.036 \\
Voltage read error (experiment) & 0.036 \\
RTD 1 Bias & 0.020 \\
RTD 2 Bias & 0.020 \\
Regression prediction error & 0.087 \\
\hline Total Bias & 0.100 \\
\hline
\end{tabular}

The following chapter will discuss the methods chosen to calculate the uncertainty margins for derived quantities such as thermal power, electrical power, and thermal efficiency. The primary measurement bias described for each instrument will be propagated into the derived quantities of interest for selected configurations and sampling intervals. 


\section{Chapter 4}

\section{Uncertainty Analysis}

This chapter will describe the methodology adopted to propagate the measurement bias errors previously described in order to develop uncertainty margins for derived quantities such as thermal power, thermal efficiency, electrical power, and total efficiency of a micro-cogeneration device.

\subsection{Propagation of Errors into Derived Quantities}

Generally speaking, an uncertainty analysis should treat the two following types of errors. The first is the precision error $S_{i}$ which aims to capture the random error that is observed during an experiment while the second is the bias error $B_{i}$ which corresponds to the repeatable uncertainty margin of a particular sensing element. An individual sensor may be subject to a number of different bias sources which can be combined into a total measurement bias using a root mean square approach shown below:

$$
B_{i}=\sqrt{\sum_{j} B_{j}{ }^{2}}
$$

Pulse output devices are a good example of sensors having a bias resulting from more than a single source. The accuracy of the pulse output measurement devices described previously only accounts for the uncertainty between the actual measured quantity and the number of pulses produced. Because the system used to record the pulses can only register integer values, an additional source of error is created. When 
only a small number of pulses is registered over a particular sampling interval, the error associated with missing a fraction of a pulse may be significant. In some cases, this quantity may be larger than that of the error resulting from the accuracy of the sensor. In order to treat this error, an additional independent bias error of one pulse was added to every measurement. This source of error becomes less significant when the pulse rate is high or the sampling interval is large.

Once the total bias for each primary measurement has been computed, a total bias for the derived quantity of interest can be calculated by taking the summation of the root mean square of each measurement bias source weighted by a sensitivity factor. The required sensitivity factor can be obtained by taking the partial derivative of the derived quantity with respect to the measured value of interests. This factor is a function of the other parameters $\left(P_{i}\right)$ used to calculate the derived quantity as shown below:

$$
\theta_{i}=f\left(P_{1}, P_{2} \ldots P_{i}\right)
$$

The values of $P_{i}$ are specific to average value of the derived quantity $(r)$ observed over the sampling interval. The sensitivity factor can then be found using the following:

$$
\theta_{i}=\frac{\partial r}{\partial P_{i}}
$$

The total bias for the derived quatity can be obtained by combining each individual measurement bias weighted by the calculated sensitivity factors:

$$
B_{T}=\sqrt{\sum_{j}\left(\theta_{i} B_{i}\right)^{2}}
$$

The precision error for average derived quantities $(\bar{S})$ can be calculated using the standard deviation $(S)$ and the number of instantaneously derived measurement quantities $(N)$ recorded over a sampling interval as follows: 


$$
\bar{S}=\frac{S}{\sqrt{N}}
$$

Finally, an overall uncertainty margin for the average derived quantity can be found by combining the total bias error and precision error weighted by a Student $\mathrm{T}$ statistic $(t)$ using the following equation:

$$
\bar{U}=\sqrt{B_{T}{ }^{2}+t \bar{S}}
$$

The confidence interval for the calculated uncertainty margin will be dependent on the confidence level selected for the Student $T$ statistic. This method is consistent with that developed by the American Society of Mechanical Engineers and was adopted for calculation of experimental uncertainty for all derived quantities [23]. A 95\% confidence level was selected for the calculation of all derived uncertainty margins presented in this work.

The following sections will employ the methodology described above to develop bias errors for the measurement of thermal power, electrical power, thermal efficiency and total efficiency of micro-cogeneration devices. A number of operating points and sampling intervals will be considered to demonstrate the full range of bias errors resulting from the instrumentation chosen.

\subsection{Thermal Power Measurement Bias Error}

The following analysis will treat only the bias errors to provide a relative comparison of the uncertainty attainable for specific derived quantities resulting from likely operating conditions produced by the testing facility. The total uncertainty including the precision error is dependent on the nature of the specific experiment being conducted and the ability of the facility to maintain the required steady state conditions.

The bias error for thermal power $\left(Q_{t h}\right)$ measurement is sensitive to both the mass flow rate of the heat recovery fluid and the temperature differnce across the measuring points. Thermal power can be calculated using the following equation: 


$$
Q_{t h}=\dot{m} c_{p} \Delta T
$$

where $\dot{m}$ and $c_{p}$ are the mass flow rate and heat capacity of water, and $\Delta T$ is the change in temperature across a component as measured by the thermopiles. Although the flow rate in each loop is constant, the bias for this parameter will change based on the sampling interval. The meters used to measure volume flow were calibrated to have an accuracy of $1 \%$ of reading $\left(B_{\dot{m} a}\right)$ while the bias error associated with reading the pulse output can be calculated using the following:

$$
B_{\dot{m} p}=1 / k t
$$

where $k$ is the pulse rate in pulses per liter and $t$ is the sampling interval in seconds. The total bias can be obtained by combining both sources of error:

$$
B_{\dot{m}}=\sqrt{B_{\dot{m} a}^{2}+B_{\dot{m} p}^{2}}
$$

In order to estimate the sensitivity factors, a number of typical operating points were considered. The two flow circuits that were chosen as representative were the loop directly connected to the cogeneration device and the loop used to impose a thermal load on the tanks (refer to Figure 2.4 for a description of these circuits). Each loop was characterised by a different flow rate and values were calculated over the entire range of heat transfer expected. The exercise was repeated using different sampling intervals in order to capture the added bias from the flow meter pulse output. The sensitivity factors used to propagate the primary measurement errors were calculated as follows:

$$
\theta_{\dot{m}}=\frac{\partial Q_{t h}}{\partial \dot{m}}=c_{p} \Delta T
$$




$$
\theta_{\Delta T}=\frac{\partial Q_{t h}}{\partial \Delta T}=\dot{m} c_{p}
$$

A constant value of $4.186 \mathrm{~kJ} / \mathrm{kgK}$ was chosen for the heat capacity of water as this value is know to change less then $0.3 \%$ over the entire range of temperatures observed on the hydraulic test bench. The product of the uncertainty and the sensitivity factor for this parameter is small compared to the other factors used to calculate thermal power and was not included in the calculation for the bias error. Finally the individual measurement bias sources and associated sensitivity factors can be combined to produce the total bias for the derived value of thermal power:

$$
B_{Q_{t h}}=\sqrt{\sum_{j}\left(\theta_{i} B_{i}\right)^{2}}
$$

Table 4.1: Thermal power bias

\begin{tabular}{ccccc}
\hline $\begin{array}{c}\text { Flow Rate } \\
(\mathrm{L} / \mathrm{min})\end{array}$ & $\begin{array}{c}\text { Thermal Power } \\
(\mathrm{kW})\end{array}$ & $\begin{array}{c}\Delta T \\
\left({ }^{\circ} \mathrm{C}\right)\end{array}$ & $\begin{array}{c}\text { 1-s Sampling } \\
\text { Bias(\%) }\end{array}$ & $\begin{array}{c}\text { 60-s Sampling } \\
\text { Bias(\%) }\end{array}$ \\
\hline \multicolumn{5}{c}{ Micro-cogeneration loop } \\
\hline 30 & 2 & 0.95 & 12.3 & 12.0 \\
30 & 5 & 2.38 & 5.5 & 4.92 \\
30 & 10 & 4.78 & 3.0 & 2.61 \\
30 & 20 & 9.55 & 3.0 & 1.6 \\
30 & 40 & 19.11 & 2.8 & 1.2 \\
\hline \multicolumn{5}{c}{ Tank loading loop } \\
\hline 18 & 2 & 1.59 & 8.2 & 7.3 \\
18 & 5 & 3.98 & 4.9 & 3.1 \\
18 & 10 & 7.96 & 4.2 & 1.8 \\
18 & 20 & 15.92 & 4.0 & 1.2 \\
\hline
\end{tabular}

The total bias errors for the cases considered are reported as a percentage of the 
thermal power being measured and are listed in Table 4.1. When the measured thermal power is relatively small, the error from the temperature measurement $\left(0.1^{\circ} \mathrm{C}\right)$ dominated the uncertainty and very little difference between the sampling intervals can be observed. Given the fact that the flow rate is held constant, the relative error from the constant temperature bias is reduced as larger temperature differences are encountered and the error on the mass flow rate becomes more significant. As the measured thermal power is increased, the effect of sample interval length becomes more apparent.

The following section will demonstrate how the thermal power bias is combined with the error from the natural gas measurement to obtain an estimate of the error for thermal efficiency calculations.

\subsection{Thermal Efficiency Bias Error}

An uncertainty analysis was repeated to determine the bias error on the calculation for the thermal efficiency $\left(\eta_{t h}\right)$ of the natural gas heater over its complete operating range. The efficiency of the natural gas heater is calculated as the ratio of thermal power added to the fluid stream over the molar heat rate $\left(\dot{n} L H V_{m}\right)$ of energy used to fuel the device as shown below:

$$
\eta_{t h}=\frac{Q_{t h}}{\dot{n} L H V_{m}}
$$

The molar heat rate into the natural gas heater can be approximated using the measured values of gas temperature $\left(T_{g}\right)$, pressure $(P)$ and volume flow rate $(\dot{V})$ as follows:

$$
\dot{n}=\frac{P \dot{V}}{R T_{g}}
$$

Equation 4.13 can be expanded to include the individual measured quantities used to derive the thermal efficiency. 


$$
\eta_{t h}=\frac{\dot{m} c_{p} \Delta T R T_{g}}{P \dot{V} L H V_{m}}
$$

The sensitivity factors required to propagate the measurement errors into the thermal efficiency are derived below:

$$
\begin{gathered}
\theta_{\dot{m}}=\frac{\partial Q_{t h}}{\partial \dot{m}}=\frac{c_{p} \Delta T R T_{g}}{P \dot{V} L H V_{m}} \\
\theta_{\Delta T}=\frac{\partial Q_{t h}}{\partial \Delta T}=\frac{\dot{m} c_{p} R T_{g}}{P \dot{V} L H V_{m}} \\
\theta_{T_{g}}=\frac{\partial Q_{t h}}{\partial T_{g}}=\frac{\dot{m} c_{p} \Delta T R}{P \dot{V} L H V_{m}} \\
\theta_{P}=\frac{\partial Q_{t h}}{\partial P}=-\frac{\dot{m} c_{p} \Delta T R T_{g}}{P^{2} \dot{V} L H V_{m}} \\
\theta_{\dot{V}}=\frac{\partial Q_{t h}}{\partial \dot{V}}=-\frac{\dot{m} c_{p} \Delta T R T_{g}}{P \dot{V}^{2} L H V_{m}} \\
\theta_{L H V_{m}}=\frac{\partial Q_{t h}}{\partial L H V_{m}}=-\frac{\dot{m} c_{p} \Delta T R T_{g}}{P \dot{V} L H V_{m}^{2}}
\end{gathered}
$$

Using the sensitivity factors, the bias error was calculated and is reported as a percentage of thermal efficiency for different power levels and sampling intervals. The results proved to be insensitive to the $c_{p}$ of water and its uncertainty. These values can be found in Table 4.2. The maximum flow rate through the unit is restricted to $18 \mathrm{~L} / \mathrm{min}$ due to the limitations of the pump. A lower heating value of $800 \mathrm{~kJ} / \mathrm{kmol}$ was chosen for natural gas and this value was assumed to be known within $2 \%$ of 
the chosen value. The resolution error from the pulse output on the natural gas me-

Table 4.2: Thermal efficiency bias errors

\begin{tabular}{ccccc}
\hline $\begin{array}{c}\text { Flow Rate } \\
(\mathrm{L} / \mathrm{min})\end{array}$ & $\begin{array}{c}\Delta T \\
\left({ }^{\circ} \mathrm{C}\right)\end{array}$ & $\begin{array}{c}\text { 1-s Sampling } \\
\text { Bias(\%) }\end{array}$ & $\begin{array}{c}\text { 15-s Sampling } \\
\operatorname{Bias}(\%)\end{array}$ & $\begin{array}{c}\text { 60-s Sampling } \\
\text { Bias(\%) }\end{array}$ \\
\hline \hline 18 & 2 & 13.6 & 2.9 & 2.6 \\
18 & 10 & 7.7 & 2.3 & 2.1 \\
18 & 20 & 5.1 & 2.1 & 2.0 \\
18 & 30 & 4.3 & 2.0 & 1.9 \\
18 & 45 & 3.9 & 1.9 & 1.9 \\
\hline
\end{tabular}

ters dominates the uncertainty for 1-second sampling intervals. For sample intervals longer than 15 seconds the pulse resolution errors converge to an almost negligible value. As the sampling interval is increased to 60 seconds, the errors attributed to both gas and water flow is reduced and the error caused by the temperature difference measurement becomes more significant. The bias from the natural gas temperature and pressure were also included in the calculations for completeness although their contributions are small.

Figure 4.1 illustrates the distribution of the different sources of bias error contributing to the total bias error for the calculation of thermal efficiency. It was assumed that measurements were taken at 30 second intervals and that the HHV of the fuel was known to within $2 \%$ of its true value. The values were calculated by taking the product of the measurement bias error and their respective sensitivity factor for each operating point. The contribution from the temperature difference measurement varies strongly as a function of thermal power while the other quantities remain almost constant. The uncertainty of the fuel's HHV dominates the error for all operating points. Further reduction of the total bias error would require a reduction in the temperature difference measurement error (especially at lower thermal power) and a lower uncertainty with respect to the heating value for natural gas. 


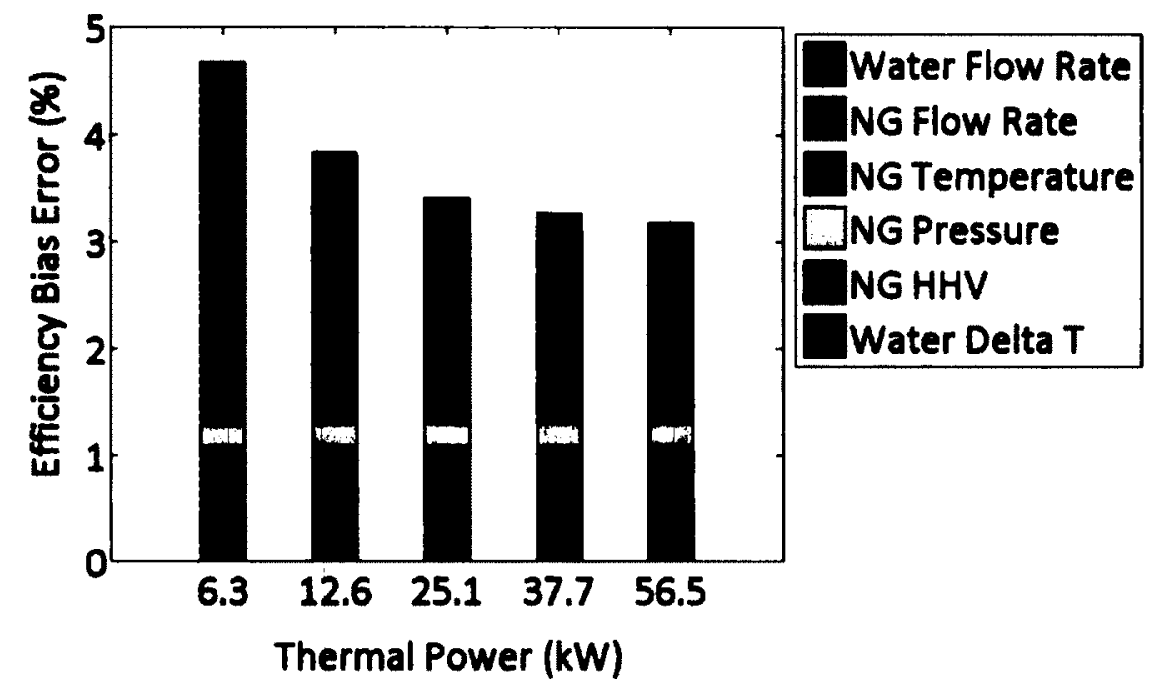

Figure 4.1: Temperature sensor differences

\subsection{Electrical Power Measurement Bias Error}

This section will aim to describe how electrical power is derived using the chosen instrumentation and how its bias error is calculated. The instantaneous electrical power $\left(P_{e}\right)$ produced or consumed by a device can be estimated using the measured current $(I)$, voltage $(V)$, and the phase angle $(\theta)$ between the two quantities as shown below:

$$
P_{e}=I V \cos \theta
$$

Because the programmable load and the baseboard heaters used in the faclilty provide purely resistive loading, the phase angle between voltage and current is zero allowing the power calculation to be simplified to the following equation:

$$
P_{e}=I V
$$

The expression shown above cannot be used directly for power measurement because the energy transducers chosen measure the electrical energy consumption rather than 
power. An estimate of electrical power can only be made by counting the number of pulses over a specific sampling interval. Under this measurement scheme, the two sources contributing to the power measurement error are the total bias of the energy meter $\left(B_{E}\right)$ and the linearity error of the current transducers $\left(B_{I A}\right.$ and $\left.B_{I B}\right)$ used to measure the current on both live phases. Although the use of current transducers also introduces a phase shift error, this was not included as a source of bias because the energy meter was specifically designed to compensate for this source. The bias errors resulting from the meters and the current transducers can be combined to calculate the total electrical power bias as shown below:

$$
B_{P e}=\sqrt{B_{E}^{2}+\left(\theta_{I A} B_{I A}\right)^{2}+\left(\theta_{I B} B_{I B}\right)^{2}}
$$

The errors caused by the accuracy of the transducers placed on each of the live phases were taken to be independent and the sensitivity factor required to propagate this bias source into the electrical power measurement error is calculated as follows:

$$
\theta_{I A}=\theta_{I B}=\frac{\partial P_{e}}{\partial I}=V
$$

The bias from the energy meters can be further decomposed into an accuracy bias $\left(B_{E a}\right)$ and a pulse resolution bias $\left(B_{E p}\right)$. The total bias resulting from the energy meter can obtained by combining the two values as shown below. Since its output is proportional to the power being measured, a sensitivity factor is not required.

$$
B_{E}=\sqrt{B_{E a}^{2}+B_{E p}^{2}}
$$

Ultimately, the bias error on the power measurement was dominated by the resolution of the energy meter. Although the units have good accuracy, they are built for longterm measurements and lack the precision needed for very short sampling intervals. Even at 10 second sampling intervals, the resolution error from the pulse output is an order of magnitude larger than other sources of error. Despite this observation, reasonable estimates of power can be made provided the sampling interval is greater 
then 10 seconds. The following section will describe how the electrical power bias error is propagated into the electrical and total efficiencies for a micro-cogeneration device.

\subsection{Micro-cogeneration Efficiency Bias Error}

An uncertainty analysis was performed to estimate the bias errors for the electrical, thermal, and total efficiencies of a $6 \mathrm{~kW}$ micro-cogeneration unit being loaded on the hydraulic test bench. The LHV value and its bias used in this analysis were assumed to be the same as the ones previously described for the natural gas heater efficiency while the flow rate assumed for heat recovery was increased to $30 \mathrm{~L} / \mathrm{min}$ in order to reflect the performance of the pump on the line that would be used for heat recovery. Only the electrical and total efficiency bias errors will be treated in this section as the method developed for the natural gas heater thermal efficiency applies equally to the micro-cogeneration device.

The electrical efficiency $\left(\eta_{e}\right)$ of the micro-cogeneration device is calculated as the ratio of electrical power produced over the molar heat rate of energy used to fuel the device as shown below:

$$
\eta_{e}=\frac{P_{e} R T_{g}}{P \dot{V} L H V_{m}}
$$

In order to propagate the measured average quantities and their bias errors into the electrical efficiency the following sensitivity factors were developed:

$$
\begin{gathered}
\theta_{P_{e}}=\frac{\partial \eta_{e}}{\partial P_{e}}=\frac{R T_{g}}{P \dot{V} L H V_{m}} \\
\theta_{T_{g}}=\frac{\partial \eta_{e}}{\partial T_{g}}=\frac{P_{e} R}{P \dot{V} L H V_{m}} \\
\theta_{P}=\frac{\partial \eta_{e}}{\partial P}=-\frac{P_{e} R T_{g}}{P^{2} \dot{V} L H V_{m}}
\end{gathered}
$$




$$
\begin{gathered}
\theta_{\dot{V}}=\frac{\partial \eta_{e}}{\partial \dot{V}}=-\frac{P_{e} R T_{g}}{P \dot{V}^{2} L H V_{m}} \\
\theta_{L H V_{m}}=\frac{\partial \eta_{e}}{\partial L H V_{m}}=-\frac{P_{e} R T_{g}}{P \dot{V} L H V_{m}^{2}}
\end{gathered}
$$

As with the thermal efficiency, the individual bias sources and their sensitivity factors are combined to obtain a total bias for the electrical efficiency for the microcogeneration device.

$$
B_{P_{e}}=\sqrt{\sum_{j}\left(\theta_{j} B_{j}\right)^{2}}
$$

Finally, the total efficiency bias error for the cogeneration device can be found by combining the bias errors from both the thermal and electrical efficiencies. These sources of error were taken to be independent.

$$
B_{\eta t o t a l}=\sqrt{\eta_{t h}^{2}+\eta_{e}^{2}}
$$

Tables 4.3 - 4.5 show the bias errors for the cogeneration device efficiency over its operational range. The bias errors are listed as a percent of the efficiency at each operating point. Because many of the measurement transducers produce a pulse output, the efficiency bias errors were calculated at 10,30 and 60-second sampling intervals to determine the effect of this parameter. As the unit's electrical/thermal output and sampling interval is increased, the uncertainty for all measured and derived quantities is reduced. The difference between the bias errors calculated at 10-second and 30-second intervals is much more significant than the change observed when the interval is further increased by an additional 30 seconds. The following chapter will describe the experimental work undertaken during the commissioning phase to assess the performance of the hydraulic test bench and to determine its limitations. 
Table 4.3: Micro-cogeneration efficiency errors 10-second sampling

\begin{tabular}{ccccc}
\hline$P_{e}(k W)$ & $Q_{t h}(k W)$ & Bias $_{e}(\%)$ & Bias $_{\text {th }}(\%)$ & Bias $_{\text {total }}(\%)$ \\
\hline \hline 1 & 6.3 & 2.8 & 2.9 & 4.0 \\
2 & 7.9 & 2.3 & 2.5 & 3.4 \\
3 & 9.2 & 2.0 & 2.2 & 3.0 \\
4 & 10.3 & 1.8 & 2.1 & 2.8 \\
5 & 10.9 & 1.7 & 1.9 & 2.6 \\
6 & 12.0 & 1.6 & 1.8 & 2.5 \\
\hline
\end{tabular}

Table 4.4: Micro-cogeneration efficiency errors 30-second sampling

\begin{tabular}{ccccc}
\hline$P_{e}(k W)$ & $Q_{t h}(k W)$ & Bias $_{e}(\%)$ & Bias $_{\text {th }}(\%)$ & Bias $_{\text {total }}(\%)$ \\
\hline \hline 1 & 6.3 & 1.3 & 2.7 & 3.0 \\
2 & 7.9 & 1.2 & 2.3 & 2.7 \\
3 & 9.2 & 1.20 & 2.1 & 2.4 \\
4 & 10.3 & 1.2 & 2.9 & 2.3 \\
5 & 10.9 & 1.2 & 1.8 & 2.2 \\
6 & 12.0 & 1.2 & 1.7 & 2.10 \\
\hline
\end{tabular}

Table 4.5: Micro-cogeneration efficiency errors 60-second sampling

\begin{tabular}{ccccc}
\hline$P_{e}(k W)$ & $Q_{t h}(k W)$ & Bias $_{e}(\%)$ & Bias $_{\text {th }}(\%)$ & Bias $_{\text {total }}(\%)$ \\
\hline \hline 1 & 6.3 & 1.1 & 2.6 & 2.9 \\
2 & 7.9 & 1.1 & 2.3 & 2.6 \\
3 & 9.2 & 1.1 & 2.1 & 2.4 \\
4 & 10.3 & 1.1 & 1.9 & 2.2 \\
5 & 10.9 & 1.1 & 1.8 & 2.1 \\
6 & 12.0 & 1.2 & 1.7 & 2.0 \\
\hline
\end{tabular}




\section{Chapter 5}

\section{Commissioning}

\subsection{Controlled Loading}

This section will aim to describe the control strategies implemented and the testing performed to commission the systems employed to provide thermal loading on the hydraulic test bench. The test bench can be configured to subject a micro-cogeneration device to both steady-state and varying inlet conditions by varying the temperature and flow rate of the coolant used for heat recovery. Heat can be directly added to the flow stream through the inline electric resistance heater or rejected to a chiller unit through a flat plate heat exchanger to fix the temperature returning to the micro-cogeneration device. The temperature of the heat transfer fluid returning to the micro-cogeneration device can be modulated by diverting a portion of the flow around a heat exchanger. The hydrauylic layout of circuit is illustrated in Figure 2.4.

A closed loop PID control strategy was adopted where the process variables considered were either the temperature exiting the heat exchanger, or the thermal power dissipated through it. Tuning of the system used to control the response of the proportional valve (V-2) was required to achieve acceptable performance. A number of load profiles were analyzed including steps, ramps and steady state runs, to select the appropriate PID parameters, and control sampling frequency. Ultimately a compromise was made between the response of the system and the relative overshoot that is acceptable.

It is also notable that the maximum rotational speed of the actuator is fixed and only its position can be varied over time. The drive system selected takes roughly 60 seconds to complete one full $90^{\circ}$ rotation where the flow stream is completely diverted around the exchanger. The maximum rate at which the by-pass fraction can 
be varied limits the ability of the test bench to vary the loading or to maintain a specified return temperature.

In order to access the dynamic response of the system, the test bench was configured to reproduce a sinusoidal temperature profile. The by-pass fraction around HX-3 was continuously varied to control the temperature returning to the storage tank. Figure 5.1 shows a comparison between the desired return temperature and that measured in real time. The control system was able to maintain the temperature to within a couple degrees of the target value over the course of the test.

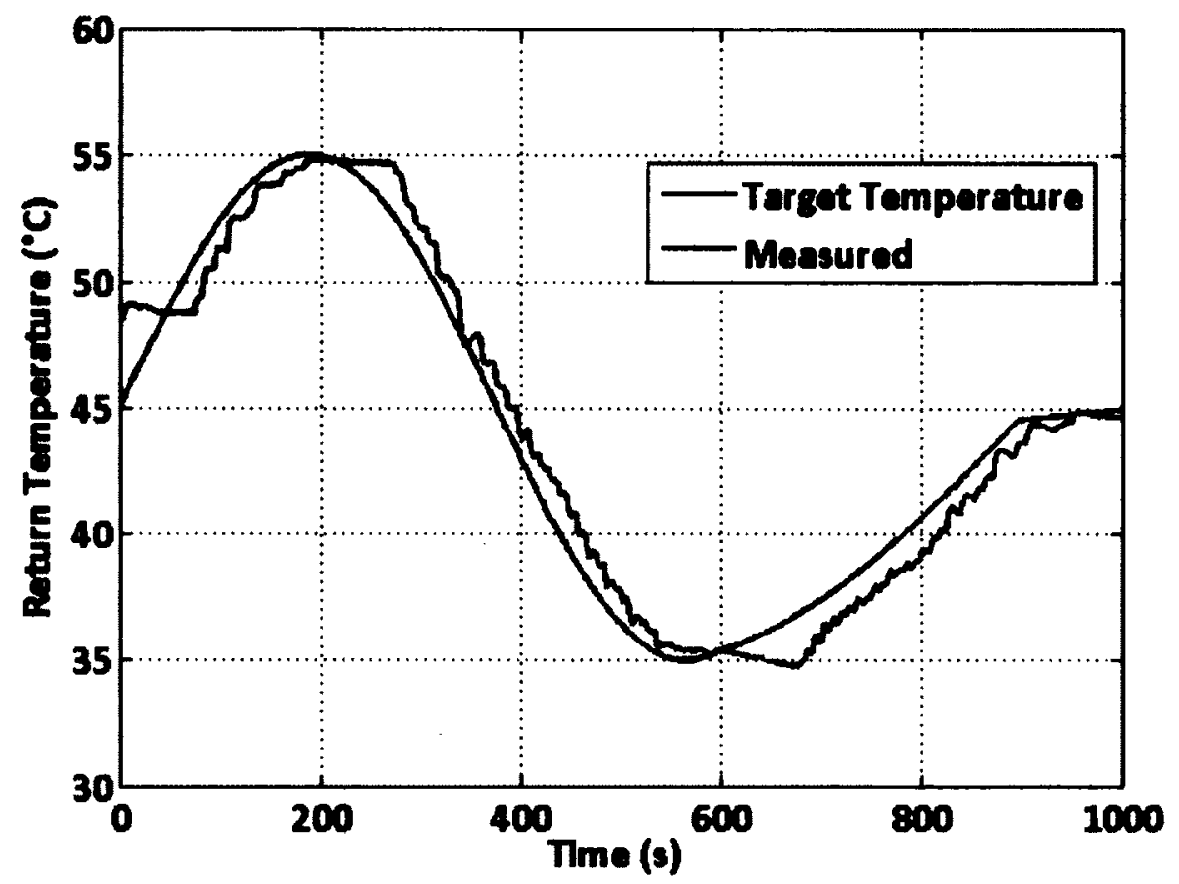

Figure 5.1: Tank return temperatures

The hydraulic test bench can also be configured to reproduce time-varying home heating and domestic hot water loads in order to evaluate system level performance under typical operation. Thermal loading of the storage tanks is simulated by varying the volume of flow through HX-2. Another DAQ-controlled proportional valve (V1) placed upstream of the heat exchanger diverts a portion of the flow in order to dynamically modulate the amount of thermal power dissipated (refer to Figure 2.4 for an illustration of the system). Careful tuning of the control parameters was required to ensure that the desired load profiles could be accurately reproduced. A number of 
load profiles were tested in order to select parameters that provided balanced control. Figure 5.2 shows a plot comparing the target load profile with the one measured in real time. Overall, the system responded rapidly and maintained good agreement with the desired loading.

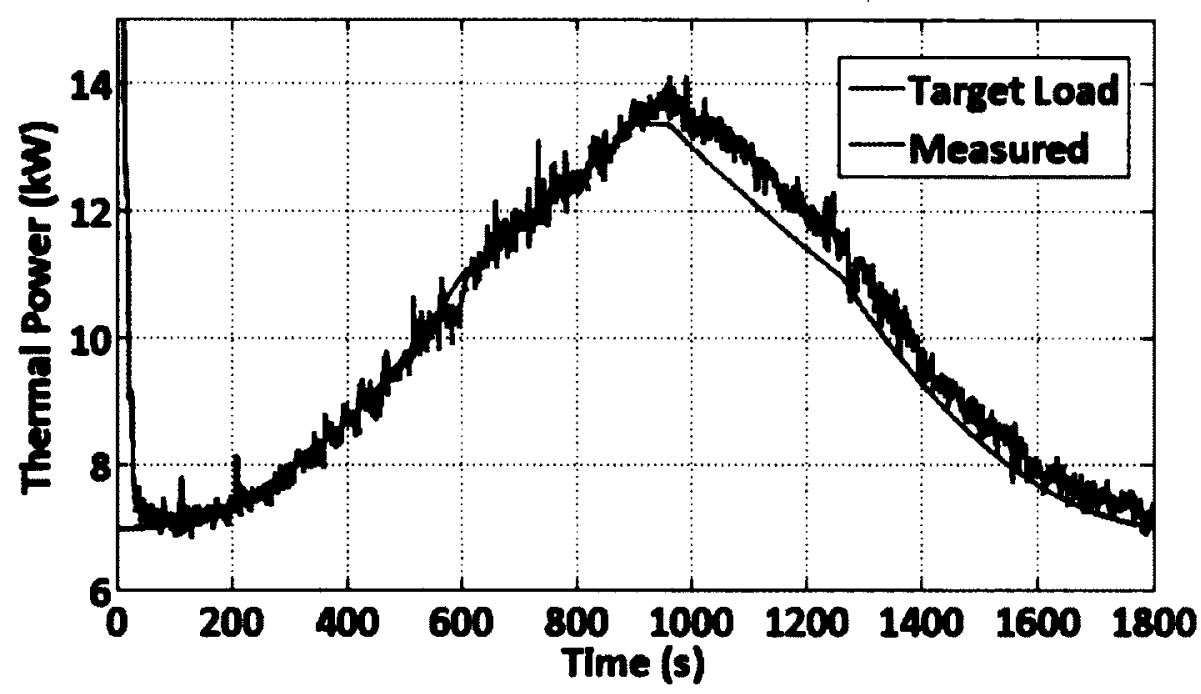

Figure 5.2: Rate of heat tranfer to thermal load

The maximum thermal loading possible on this circuit is limited by the operating temperature of the thermal storage and the capacity of the pump used to circulate water through the exchanger. With the thermal storage tank charged to $80^{\circ} \mathrm{C}$ and a flow rate of $0.3 \mathrm{~L} / \mathrm{s}$, the maximum thermal power dissipated through the heat exchanger is $20 \mathrm{~kW}$. Currently, both the space heating loads and the domestic hot water loads are realized by dissipating heat through a single flat plate exchanger. Under this scheme, residential loads must be simulated by imposing a combined load profile executed at some predefine time interval. The rate at which this load can be varied over time is restricted by the speed of the valve drive. Domestic hot water draws are known to vary widely over time making them difficult or in many cases, impossible to reproduce using the loading system. Synthetic combined load profiles based on real loads would have to be created at time intervals that are sufficiently large to be reproduced consistently. The parameters chosen for control of both variable loads can be found in Table 5.1. 
Table 5.1: PID control parameters

\begin{tabular}{lccc}
\hline Circuit & P & I & D \\
\hline \hline Tank Loading Loop & 0.97 & 0.30 & 0.07 \\
Heat Recovery Loop & 1.20 & 0.30 & 0.06 \\
\hline
\end{tabular}

The following section will describe a commissioning exercise undertaken to measure the heat lost through the hydraulic test bench and to independently validate the temperature measurements taken using the calibrated instruments.

\subsection{Tank Heat Balance and Sensor Comparison}

Testing was conducted during the commissioning phase to determine the magnitude of the thermal losses from one of the circuits used to load the tank, and to compare measurements of thermal power to verify the output from the thermopiles and thermocouples. Figure 5.3 illustrates the configuration chosen for the experiment. Thermal power was measured across the inlet and outlet of the storage tank and across the heat exchanger used as the load. The heat loss from the remainder of the circuit was calculated from the difference between these two values. Thermal power provided from the storage tank and dissipated through the test bench was calculated separately at each point using the output from the thermopiles (TP-3 \& TP-1) and the independent temperature measurements of the thermocouples placed across the four points of interest (TC-1A and TC-1B \& TC-3A and TC-3B).

Prior to the experiment, the storage tank was filled through the flow meter to a known volume of $560 \mathrm{~L}$ and a thermocouple rack was placed in the tank to record the temperature at four different heights. Three separate steady state runs, each 10 minutes in length, were conducted to generate a suitable data set. The by-bass fraction across the heat exchanger was varied between runs to access its effect on the heat loss from the pipe network. Over the course of each run, the temperatures, temperature differences and flow rates were measured every second to produce an estimate of instantaneous thermal power. In an effort to validate the power measurements, the total heat removed from the tank over each run was also compared to the integrated power measurements. The heat removed from the tank was calculated based on the 


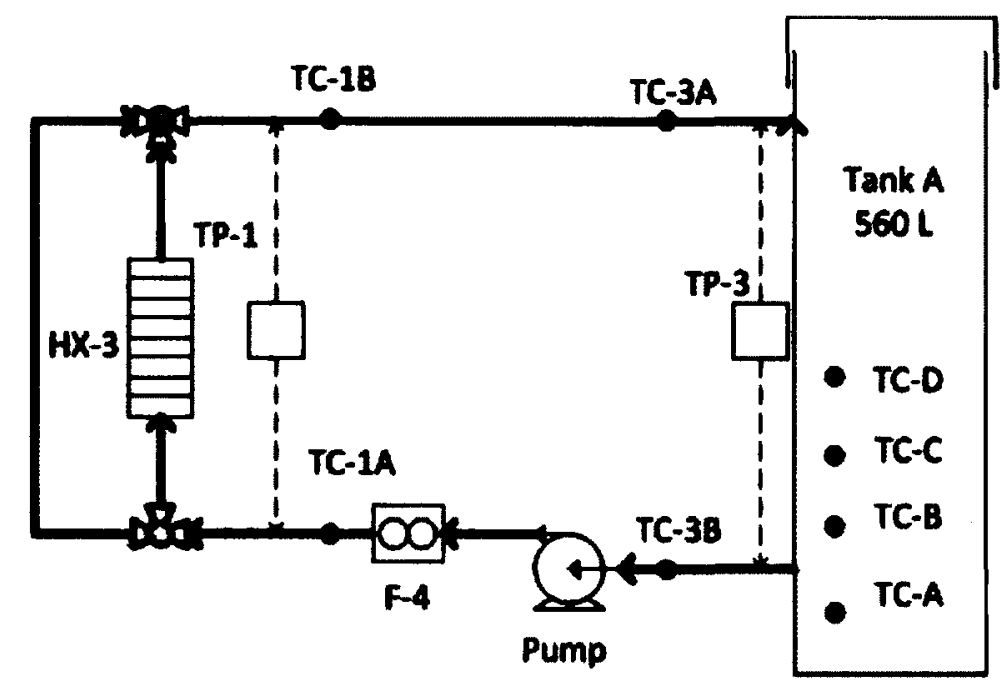

Figure 5.3: Heat balance experiment configuration

differences in the average tank temperatures at the beginning and end of each run. Table 5.2 shows the total heat loss for each of the runs calculated using the average temperature change of the tank, the output from the thermopiles and the output from the thermocouples. The pipe losses are listed as a fraction of the energy measured across the inlet and outlet of the tank.

Table 5.2: Test bench losses

Heat Exchanger By-pass Fraction

\begin{tabular}{lccc}
\hline Measurement Location & $66(\%)$ & $33(\%)$ & $0(\%)$ \\
\hline \hline Tank Average Temperature (MJ) & $6.4 \pm 1.2$ & $17.7 \pm 1.2$ & $24.2 \pm 1.2$ \\
Tank Thermopile (MJ) & $6.2 \pm 0.2$ & $17.3 \pm 0.5$ & $23.8 \pm 0.7$ \\
Tank Thermocouples(MJ) & $6.1 \pm 1.0$ & $17.3 \pm 1.1$ & $23.5 \pm 1.2$ \\
Heat Exchanger Thermopiles (MJ) & $5.4 \pm 0.2$ & $16.9 \pm 0.5$ & $23.3 \pm 0.7$ \\
Heat Exchanger Thermocouples (MJ) & $5.4 \pm 1.0$ & $17.1 \pm 1.1$ & $23.6 \pm 1.2$ \\
Pipe Losses Thermopiles (\%) & $12.6 \pm 4.0$ & $2.3 \pm 4.0$ & $1.9 \pm 4.0$ \\
Pipe Losses Thermocouples (\%) & $9.8 \pm 23.0$ & $1.0 \pm 14.0$ & $-0.20 \pm 7.0$ \\
\hline
\end{tabular}

A number of trends can be observed when considering the results from the three 
trials. The energy removed from the tank calculated using the bulk properties corresponded well with those taken using either the thermopiles or the thermocouples placed directly down-stream of the tank. As the by-pass fraction was reduced, a greater portion of the heat being drawn from the tank was dumped through the exchanger and the fraction of the heat losses from the piping was greatly reduced. The thermal power lost between the two measuring points ranged between $0.66 \mathrm{~kW}-1.3$ $\mathrm{kW}$ and decreased as a function of the power being consumed through the exchanger. This may be partially attributed to a lower average difference between the fluid circuit temperature and the ambient temperature. Although this trend can be observed, the actual thermal power measured from the difference between the two sets of sensors was smaller than the uncertainty of this measured quantity. The aggregate results show that the losses occurring between the measurement points on the test bench are relatively small and could be ignored for most experiments.

In order to addess the consistency of the temperature measurements, the temperature differences measured by the thermopiles and the pairs of thermocouples were compared for the three different runs. The thermocouple temperature measurements were taken to be independent and the total bias for the temperature difference was obtained by combining the two individual bias errors using a root mean square approach. Each thermocouple has a bias error of $0.5^{\circ} \mathrm{C}$ resulting in a total bias error of $0.7^{\circ} \mathrm{C}$ for a temperature difference measurement. The thermopiles measure a temperature difference directly with a bias error of $0.1^{\circ} \mathrm{C}$.

Figure 5.4 shows the frequency distribution of the difference between the temperature differences calculated using the measurements from the thermopile and the thermocouple pairs over the length of each run. It can be observed that the differences between the temperature differences all fell within the possible bias error for the thermocouples. This provides an indication that the sensors are functioning as expected and that their measurements can be used with confidence. It is also notable that a large majority of the difference measurements recorded using both sensor types fall within the uncertainty margins of the thermopiles. The result suggests that the uncertainty margins calculated for temperature measurement using the thermocouples was conservative.

The following section will describe an experiment undertaken to characterise the thermal efficiency of the instantaneous natural gas heater as a function of the inlet water temperature. 


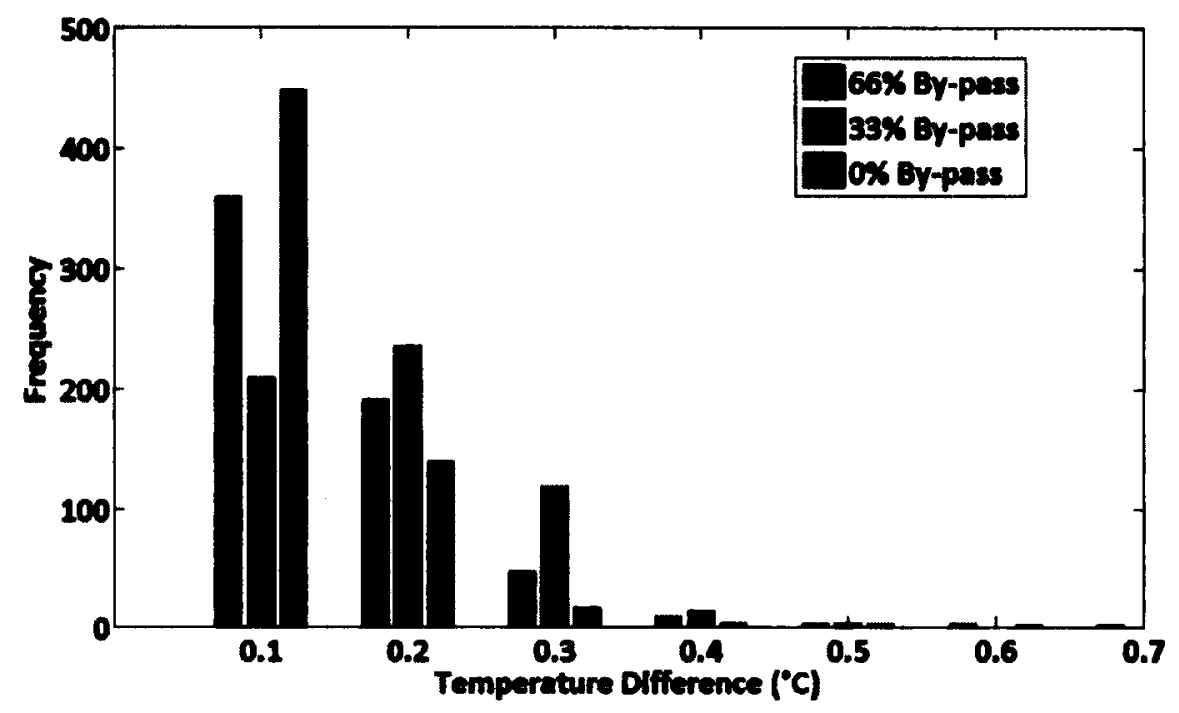

Figure 5.4: Temperature sensor differences

\subsection{Natural Gas Heater Efficiency}

The instantaneous natural gas heater used to supplement the thermal output from the micro-cogeneration device has a rated thermal efficiency of $98 \%$ (HHV). The unit has a secondary gas-to-water heat exchanger used to recover heat from the exhaust stream when operated under condensing conditions. A number of tests were conducted to determine the device's actual thermal efficiency as a function of the inlet water temperature. To calculate the thermal efficiency of the heater, an estimate of the fuel's heating value was required. As it was not possible to sample the composition of the gas used in the facility, an estimate was obtained from the local natural gas provider. A heating value of $37.8 \mathrm{MJ} / \mathrm{m}^{3}$ was provided based on the volumetric composition of the gas measured daily at a site roughly $170 \mathrm{~km}$ east of Ottawa. The value provided was an average for the entire month of February and was taken as the HHV for the fuel. A copy of the gas sampling report can be found in Appendix D.

In order to fix the inlet temperature into the gas heater, the storage tank was filled to its maximum volume. Such a large volume was chosen to help reduce the increase in inlet temperatures observed during the experiments. Once the tank was heated to the desired set point, the flow was diverted through the heater and it was run for a period of roughly 60 seconds allowing steady state conditions to be reached. Once the temperature rise across the heater was constant, natural gas flow 
and water flow were measured and recorded at 10-second intervals for a period of 5 minutes. The temperature increase across the heater, and the natural gas properties were sampled every second and averaged over 10-second intervals to coincide with the flow measurements.

A total of $\mathbf{3 0}$ steady-state measurements were recorded during each trial and used to calculate thermal efficiency. The standard deviation of the derived quantity was recorded to calculate a precision error. An ordered pair of inlet temperature and thermal efficiency was calculated based on the average of the 30 data points. This procedure was repeated for a number of inlet temperatures spanning the range expected on the hydraulic test bench. Figure 5.5 shows how the thermal efficiency of the heater varies as a function of inlet water temperature. The thermal efficiency

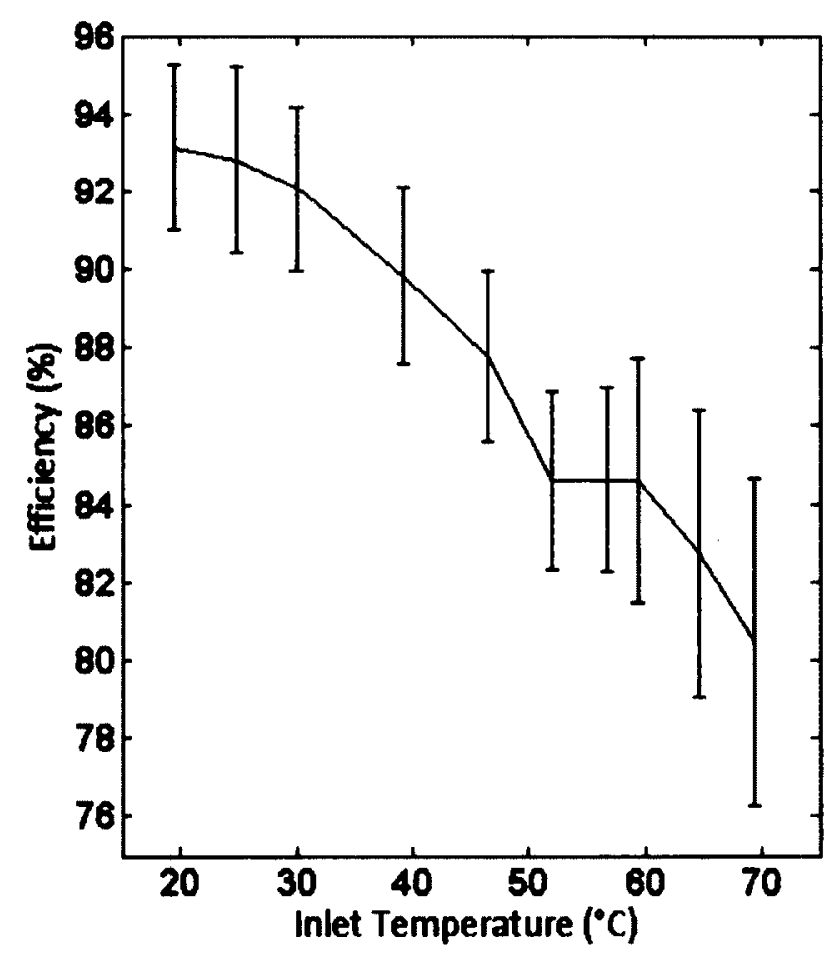

Figure 5.5: Natural gas heater efficiency

of the heater decreases as the inlet temperature is increased because less energy is recovered from the exhaust stream. A sharp decrease in efficiency is observed as the inlet temperature approaches $50^{\circ} \mathrm{C}$. Beyond this temperature the water vapour in the exhaust stream does not condense reducing the heat that is recoverable. Table 5.3 
Table 5.3: Thermal efficiency uncertainty

\begin{tabular}{ccccc}
\hline $\begin{array}{c}\text { Inlet Temp. } \\
\left({ }^{\circ} \mathrm{C}\right)\end{array}$ & $\begin{array}{c}\text { Efficiency } \\
(\%)\end{array}$ & $\begin{array}{c}\text { Bias Error } \\
(\%)\end{array}$ & $\begin{array}{c}\text { Precession Error } \\
(\%)\end{array}$ & $\begin{array}{c}\text { Uncertainty } \\
(\%)\end{array}$ \\
\hline \hline 19.5 & 93.1 & 1.9 & 0.5 & 2.1 \\
24.9 & 92.8 & 2.2 & 0.5 & 2.4 \\
30.0 & 92.1 & 2.0 & 0.4 & 2.1 \\
39.2 & 89.8 & 2.1 & 0.5 & 2.3 \\
46.5 & 87.8 & 2.1 & 0.4 & 2.2 \\
52.0 & 84.6 & 2.1 & 0.5 & 2.3 \\
56.8 & 84.6 & 2.1 & 0.5 & 2.3 \\
59.4 & 84.6 & 3.0 & 0.5 & 3.1 \\
64.7 & 82.7 & 3.4 & 0.8 & 3.7 \\
69.4 & 80.5 & 4.1 & 0.4 & 4.2 \\
\hline
\end{tabular}

shows the average measured and derived quantities during each run and provides the uncertainty for the calculated thermal efficiency. For all test runs, the uncertainty was dominated by the bias error of the instrumentation. The precission error only contributed modestly to the total uncertainty, suggesting that conditions remained stable during the experiments. As the inlet temperature approached the maximum outlet temperature of the heater, the uncertainty margins increased significantly. This is largely due to the bias error associated with the measurement of the volumetric natural gas flow, and to a lesser extent, the bias error on the temperature measurement. 


\section{Chapter 6}

\section{Conclusions and Future Work}

\subsection{Conclusions}

Meeting residential loads using micro-cogeneration technologies as an alternative to the separate production of heat and electricity can provide a meaningful reduction in secondary energy use and related greenhouse gas emissions. The magnitude of the reduction over a particular reference system is dependent on a number of buildingspecific factors including the size, construction, and age of a residence, its location and the occupant driven demand for energy services within the home. In order to fully realize the potential savings, micro-cogeneration systems must be properly sized, configured, and operated. More research is required to determine how best to integrate micro-cogeneration technologies into Canadian residences as issues related to device capacity, design of balance of plant components and control strategies remain largely unresolved.

Tools such as building performance simulation are well suited to explore and evaluate different design options; however, the validity of results from simulation based studies are dependent on the accuracy and reliability of the models employed. In light of this, a facility capable of subjecting micro-cogeneration units to controlled electrical and thermal loading was designed and commissioned in order to collect performance data suitable for device-specific model calibration. In an effort to reduce the uncertainty of temperature measurements, thermocouples and five-junction thermopiles were calibrated over the range of temperatures expected on the hydraulic test bench. Commissioning experiments were conducted to validate the temperature measurements, and to configure the systems used to provide controlled thermal boundary conditions. 
The design, construction and commissioning of the hydraulic test bench has been completed. The calibrated instrumentation, auxiliary heating systems, and plant level controls have been fully integrated with a central DAQ allowing for autonomous operation of the facility. A number of experiments were conducted during the commissioning phase to assess system level performance, identify and correct hardware integration issues, and determine the physical limitations of the facility. The test bench can be used to characterize the performance of micro-cogeneration systems and to investigate suitable balance of plant configurations, and control strategies.

\subsection{Future Work}

The conceptual design of an electrical loading and power measurement system was completed to accommodate a $6 \mathrm{~kW}$ micro-cogeneration unit. An analysis was performed to estimate the bias errors for electrical power measurement, and thermal and electrical efficiency using the assumed electrical instrumentation and the measurement devices embedded in the hydraulic test bench. To date, the micro-cogeneration unit and electrical system has not been commissioned because the unit is not certified for grid-connection in Ontario. Replacement or certification of the device's electric inverter would be required to gain approval for installation. Alternatively, the unit could be installed and operated under the supervision of the Electrical Safety Authority of Ontario to obtain a temporary operating licence. This would permit an assessment of the performance of both the electrical and thermal loading systems. Experimental testing could be undertaken to generate data suitable to calibrate a detailed model of the unit or it could be loaded using realistic electrical/thermal loads to determine its average efficiency for typical type days.

Currently, the domestic hot water and space heating loads must be combined into a single time varying load profile. The maximum thermal load that can be placed on the thermal storages is only $20 \mathrm{~kW}$ which is often smaller than the maximum aggregate load for most residences. The pump used to circulate water through this circuit is operating at its highest duty point due to losses through the pipe network. Replacing it with a pump having a higher capacity would increase the flow through the exchanger used for loading, and would increase the maximum thermal loading possible.

The composition and the heating value of the natural gas supply servicing the 
facility are known to vary over the course of a year. Thermal efficiency calculations are very sensitive to the heating value of the input fuel and its uncertainty. Sampling of the gas supply during periods where experiments are being conducted would provide better confidence in the derived efficiencies.

Electrical buffering in the form of a bank of lead-acid batteries or lithium-ion storage would also be a valuable addition to the facility as many operational strategies have been developed that employ electrical storage. 


\section{List of References}

[1] Natural Resources Canada, Energy Efficiency Trends in Canada 1990 to 2009. Canada: Government of Canada, 2011.

[2] Natural Resources Canada, Survey of Household Energy Use 2007 - Detailed Statistical Report. Canada: Government of Canada, 2010.

[3] Environment Canada, National Inventory Report Greenhouse Gas Sources and Sinks in Canada 1990-2010. Canada: Government of Canada, 2012.

[4] I. Beausoleil-Morrison, An Experimental and Simulation-Based Investigation of the Performance of Small-Scale Fuel Cell and Combustion-Based Cogeneration Devices Serving Residential Buildings Energy Conservation in Buildings. Ottawa: International Energy Agency's Energy Conservation in Building and Community Systems Program, 2008.

[5] I. Beausoleil-Morrison, Experimental Investigation of Residential Cogeneration Devices and Calibration of Models. Ottawa: International Energy Agency Energy Conservation in Buildings and Community Systems Programme, 2007.

[6] M. Bell, F. Swinton, E.Entchev, J .Gusdorf, W. Kalbfleisch, R. Marchand, F. Szadkowski, Development of Micro Combined Heat and Power Technology Assessment Capability at the Canadian Centre for Housing Technology. Ottawa: National Research Council Canada - Canadian Centre for Housing Technology, 2003.

[7] M.Manning, F.Szadkowski, J.Gusdorf, E.Entchev, F.Swinton, M.Douglas, Integration and monitoring of microCHP systems in residential application at the Canadian Centre for Housing Technology. Ottawa: National Research Council Canada - Canadian Centre for Housing Technology, 2008.

[8] K. Siemens, M. Douglas, J. Gusdorf, F. Szadkowski,E. Entchev, Field Trial of the WhisperGen Residential CHP System at the Canadian Centre for Housing Technology. Ottawa: National Research Council Canada - Canadian Centre for Housing Technology, 2005.

[9] F. Swinton, M. Manning, M. Entchev, E. Gusdorf, J. Szadkowski, Testing a Residential Fuel Cell for Combined Heat and Power The CHP System. Ottawa: Natural Resources Canada, 2006.

[10] M. K.Lombardi, Integrating a Stirling Cogeneration Appliance with a Forced Air Furnace. Natural Resources Canada-CANMET Energy, 2009. 
[11] M. M. J. Gusdorf, M.A. Dougla, M. Swinton, F. Szadkowski1, Testing a Residential System Including Combined Heat and Power and Ground Source Heat Pumps at the Canadian Center for Housing Technology. Ottawa: National Research Council Canada - Canadian Centre for Housing Technology, 2007.

[12] P. Tzscheutschler, H. Muehlbacher, Results of Experimental Measurements of Residential Cogeneration Systems. Munich: Institute for Energy Economy and Application Technology, 2008.

[13] M. A.Hawkes, "Impacts of temporal precision in optimisation modelling of microCombined Heat and Power," Energy, vol. 30, pp. 1759-1779, July 2005.

[14] A.D. Hawkes, M.A Leach, N.P. Brandon, Economic and Environmental Impacts of Micro-CHP Start-UP Performance and Turndown Ratio. London: Centre for Energy Policy and Technology, Imperial College, 2009.

[15] I. Beausoleil-Morrison, Performance Assessment of Prototype Residential Cogeneration Ssystems in Single Detached Houses in Canada. Ottawa: International Energy Agency Energy Conservation in Buildings and Community Systems Programme, 2007.

[16] H. Ribberink, I. Beausoleil-Morrison, Realistic Performance Forecast for Stirling Engine Residential Cogeneration Systems applied in Single Detached Houses in Canada. Ottawa: CANMET Energy Technology Center - Natural Resources Canada, 2009.

[17] C. D. Aussant, A. S. Fung, V. I. Ugursal, and H. Taherian, "Residential application of internal combustion engine based cogeneration in cold climate Canada," Energy and Buildings, vol. 41, pp. 1288-1298, Dec. 2009.

[18] H. Ribberink, K.Lombardi, L.Yang, E. Entchev, Hybrid Renewable Microcogeneration Energy System for Power and Thermal Generation With Reduced Emissions. Ottawa: CanmetENERGY Research Centre - Natural Resources, 2011.

[19] J. V. Bael, G. Vekemans, E. Peeters, and L. Stijnen, Small Scale Combined Heat and Power in Flanders: An Overview and Results of an Evaluated Project. No. 1, Westerlo: VITO - The Flemish Institute for Technological Research, 2009.

[20] J. Lipp and J. Jungwirth, Field Test with Stirling Engine Micro-CHP Units in Residential Buildings. Munich: Technische University, 2010.

[21] Trust, Carbon, "Micro-CHP Accelerator Final Report." 2011.

[22] Sustainable Energy Building Systems Repository, "Calibration Data." http://node1.mae.carleton.ca/ibeau_students/evan/. Accessed: 04/09/2012.

[23] R. Moffat, "Describing the Uncertainty in Experimental Results," Experimental Thermal and Fluid Science, vol. 1, pp. 3-17, 1988. 


\section{Appendix A}

\section{Electrical Drawings}

Table A.1 shows the circuit breakers used for each pump and lists the channels assigned on the digital module used for automated control (cFP-DO-400). Figure A.1 shows the electrical layout of the control and power system used to drive the pumps. The pumps can be controlled digitally using latching relays to switch a $24 \mathrm{VAC}$ control signal used to activate the pump motor starters. An external manual switch was placed in series with each motor starter to allow the pumps to be operated manually.

Table A.1: Digital ouput channels

\begin{tabular}{clcc}
\hline Pump & Breaker \# & Set Channel & Reset Channel \\
\hline \hline Pump-1 & B10-12 & 2 & 3 \\
Pump-2 & B14-16 & 6 & 7 \\
Pump-3 & B6-8 & 0 & 1 \\
Pump-4 & B2-4 & 4 & 5 \\
\hline
\end{tabular}




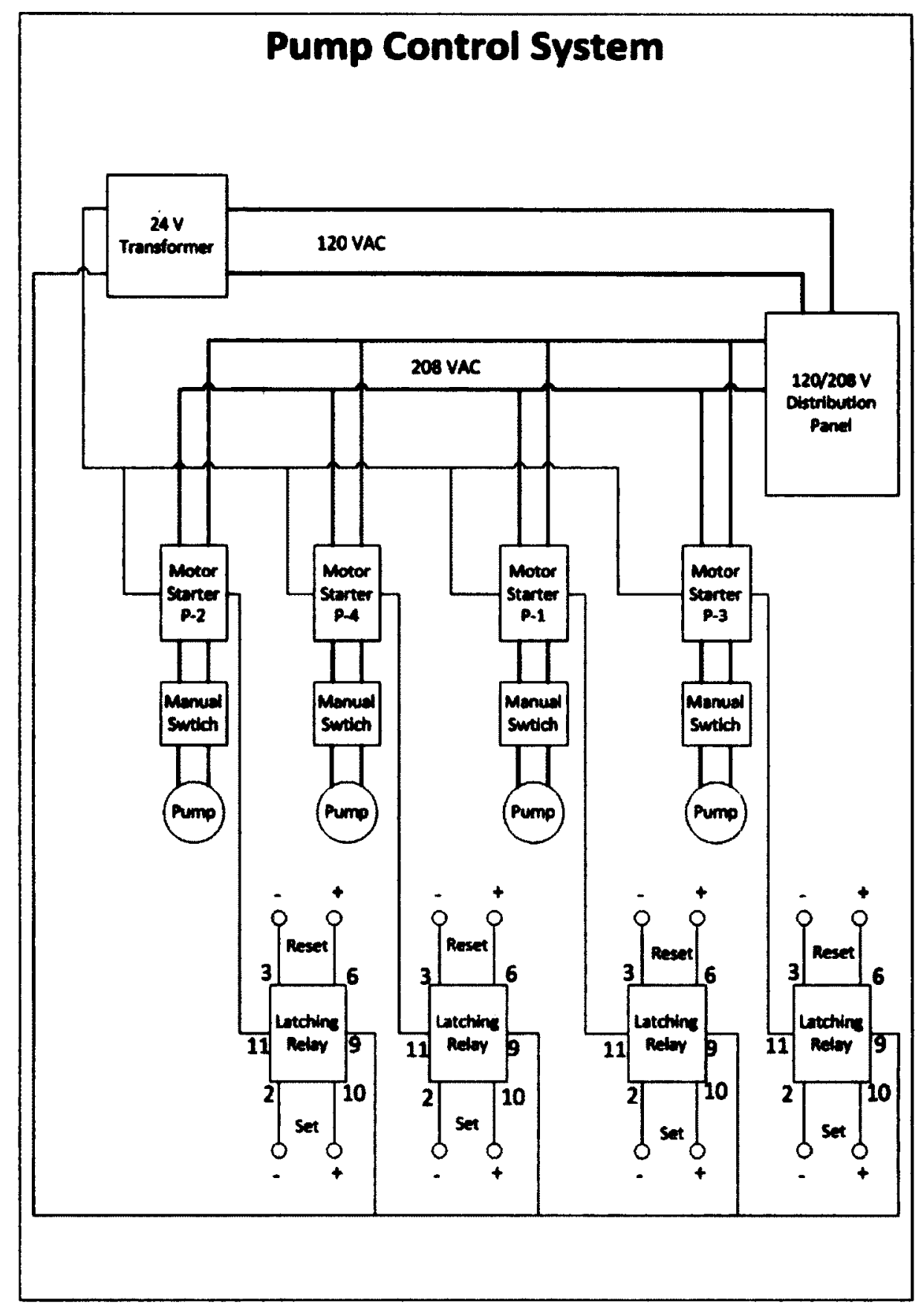

Figure A.1: Pump relay system 


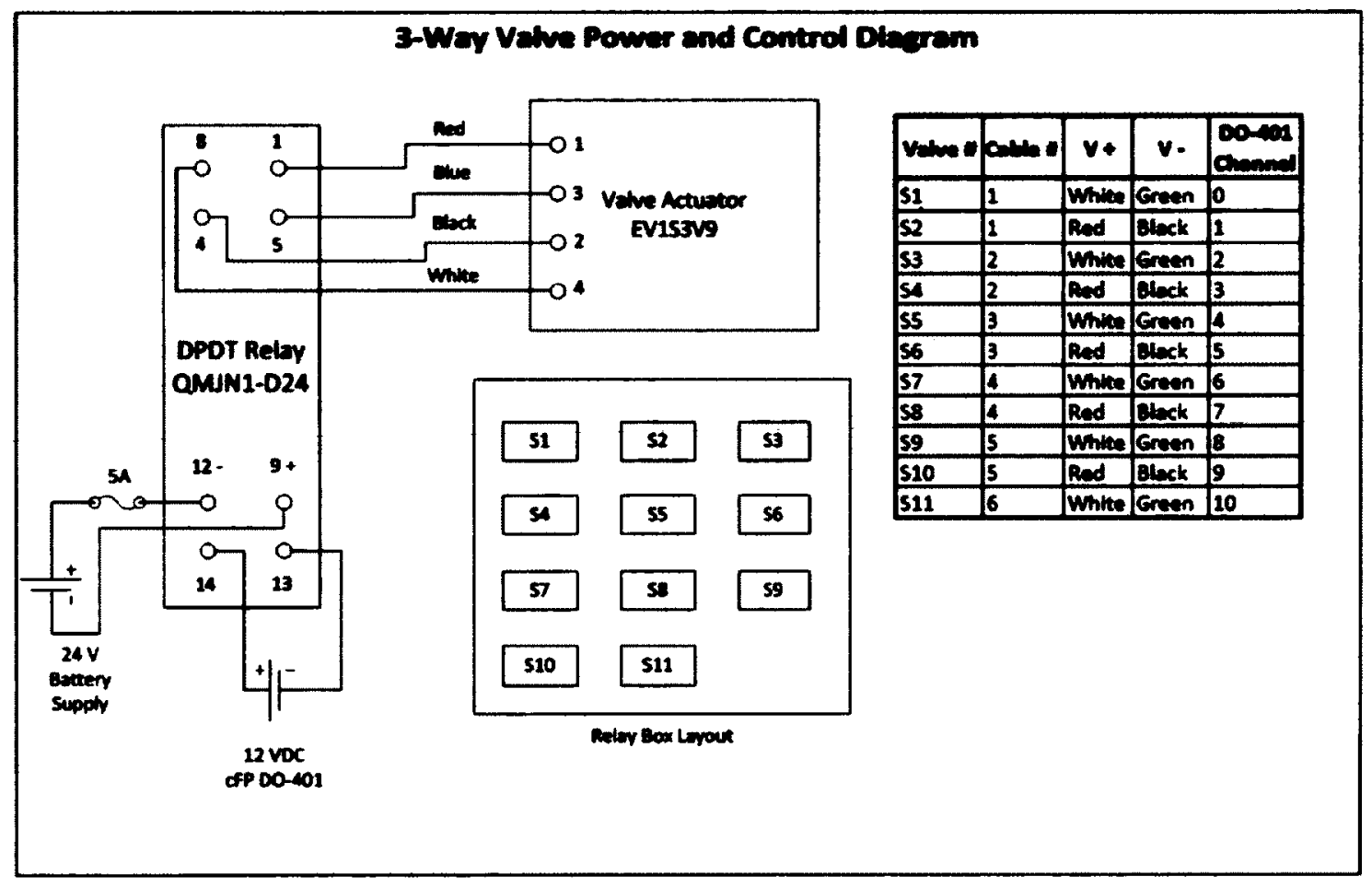

?

Figure A.2: 3-Way valve power and control diagram 


\section{Appendix B}

\section{Thermocouple Calibration Data}

The data collected during the experiment used to calibrate both thermocouple wires $\left(T C_{B L}\right.$ and $\left.T C_{B R}\right)$ is presented in Table B.1. The voltage produced by both sensors, and the temperature of the bath measured in units of resistance and ${ }^{\circ} \mathrm{C}$ are listed in the table. The standard deviation of all three measured quantities is also shown to demonstrate that the data were collected under steady state conditions.

Table B.1: Thermocouple calibration data

\begin{tabular}{ccccccc}
\hline $\begin{array}{c}\text { Resistance } \\
(\Omega)\end{array}$ & $\begin{array}{c}\text { Stdev } \\
(\Omega)\end{array}$ & $\begin{array}{c}\text { Temperature } \\
\left({ }^{\circ} \mathrm{C}\right)\end{array}$ & $\begin{array}{c}\mathrm{emf}_{B R} \\
(\mathrm{mV})\end{array}$ & $\begin{array}{c}\text { Stdev } \\
(\mathrm{mV})\end{array}$ & $\begin{array}{c}\mathrm{emf}_{B L} \\
(\mathrm{mV})\end{array}$ & $\begin{array}{c}\text { Stdev } \\
(\mathrm{mV})\end{array}$ \\
\hline \hline 100.83 & 0.00079 & 2.15 & -0.754 & 0.00064 & -0.756 & 0.00056 \\
103.99 & 0.00100 & 10.10 & -0.444 & 0.00050 & -0.444 & 0.00064 \\
107.94 & 0.00049 & 20.04 & -0.047 & 0.00009 & -0.047 & 0.00026 \\
111.87 & 0.00094 & 29.97 & 0.357 & 0.00067 & 0.358 & 0.00076 \\
115.78 & 0.00223 & 39.90 & 0.768 & 0.00076 & 0.771 & 0.00037 \\
119.68 & 0.00261 & 49.83 & 1.189 & 0.00031 & 1.192 & 0.00030 \\
123.57 & 0.00153 & 59.75 & 1.616 & 0.00052 & 1.620 & 0.00034 \\
127.44 & 0.00153 & 69.67 & 2.051 & 0.00090 & 2.056 & 0.00077 \\
131.27 & 0.00315 & 79.49 & 2.489 & 0.00122 & 2.495 & 0.00084 \\
135.07 & 0.00432 & 89.23 & 2.931 & 0.00230 & 2.939 & 0.00130 \\
\hline
\end{tabular}

The resistance values from the platinum thermometer were converted into ${ }^{\circ} \mathrm{C}$ using a curve fit of the calibration data provided by the manufacturer. The quadratic fit 
can be found below:

$$
T\left({ }^{\circ} C\right)=0.001 R^{2}+2.309 R-240.843
$$

Using a least squares regression approach, a polynomial relating the temperature and measured emf was obtained for both thermocouple wire spools. Table B.2 lists the actual bath temperatures measured along with the values predicted using the curve fits. Also listed in the table are the temperature prediction errors resulting from the use of the curve fits. The maximum error was chosen to compute the total uncertainty for temperature measurement using the calibrated thermocouples. The

Table B.2: Thermocouple regression errors

\begin{tabular}{ccccc}
\hline $\begin{array}{c}\text { Temperature } \\
\left({ }^{\circ} \mathrm{C}\right)\end{array}$ & $\begin{array}{c}\text { Temperature } \\
\left({ }^{\circ} \mathrm{C}\right)\end{array}$ & $\begin{array}{c}\text { Temperature }_{B L} \\
\left({ }^{\circ} \mathrm{C}\right)\end{array}$ & $\begin{array}{c}\text { Error }_{B R} \\
\left({ }^{\circ} \mathrm{C}\right)\end{array}$ & $\begin{array}{c}\text { Error }_{B L} \\
\left({ }^{\circ} \mathrm{C}\right.\end{array}$ \\
\hline \hline 2.15 & 2.25 & 2.13 & 0.10 & 0.01 \\
10.10 & 10.10 & 10.07 & 0.00 & 0.04 \\
20.04 & 19.99 & 19.99 & 0.06 & 0.06 \\
29.97 & 29.90 & 29.95 & 0.08 & 0.03 \\
39.90 & 39.81 & 39.92 & 0.09 & 0.01 \\
49.83 & 49.77 & 49.91 & 0.07 & 0.07 \\
59.75 & 59.69 & 59.89 & 0.06 & 0.13 \\
69.67 & 69.60 & 69.83 & 0.08 & 0.16 \\
79.49 & 79.37 & 79.64 & 0.13 & 0.15 \\
89.27 & 89.04 & 89.37 & 0.23 & 0.10 \\
\hline Max. Error & & & 0.23 & 0.16 \\
\hline
\end{tabular}

two polynomials resulting from the calibration experiment are shown below:

$$
\begin{aligned}
& T C_{B R}\left({ }^{\circ} \mathrm{C}\right)=-0.5231 e m f^{2}+24.748 e m f+21.159 \\
& T C_{B L}\left({ }^{\circ} C\right)=-0.5194 e m f^{2}+24.683 e m f+21.159
\end{aligned}
$$




\section{Appendix C}

\section{Thermopile Calibration Data}

A sample of the data collected during the experiment conducted to calibrate the 5-junction thermopiles is presented in Table C.1. The voltage produced by the thermopile, and the temperatures of each of the constant baths measured in units of resistance and ${ }^{\circ} \mathrm{C}$ are listed in the table. The standard deviation of all measured quantities is also shown to demonstrate that the data were collected under steady state conditions. Figure C.1 shows the hot-junction temperatures as a function of

Table C.1: Thermopile calibration data

\begin{tabular}{cccccccc}
\hline $\begin{array}{c}\text { emf } \\
(\mathrm{mV})\end{array}$ & $\begin{array}{c}\text { Stdev } \\
(\mathrm{mV})\end{array}$ & $\begin{array}{c}R_{\text {cold }} \\
(\Omega)\end{array}$ & $\begin{array}{c}\text { Stdev } \\
(\Omega)\end{array}$ & $\begin{array}{c}T_{\text {cold }} \\
\left({ }^{\circ} \mathrm{C}\right)\end{array}$ & $\begin{array}{c}R_{\text {hot }} \\
(\Omega)\end{array}$ & $\begin{array}{c}\text { Stdev } \\
(\Omega)\end{array}$ & $\begin{array}{c}T_{\text {hot }} \\
\left({ }^{\circ} \mathrm{C}\right)\end{array}$ \\
\hline \hline-0.0114 & 0.0010 & 119.68 & 0.0005 & 49.82 & 119.65 & 0.0010 & 48.65 \\
1.0502 & 0.0009 & 119.68 & 0.0005 & 49.83 & 121.60 & 0.0006 & 53.61 \\
2.1196 & 0.0017 & 119.68 & 0.0008 & 49.83 & 123.54 & 0.0026 & 58.54 \\
3.1941 & 0.0010 & 119.69 & 0.0010 & 49.83 & 125.47 & 0.0012 & 63.45 \\
4.2829 & 0.0013 & 119.70 & 0.0009 & 49.87 & 127.41 & 0.0012 & 68.41 \\
5.3743 & 0.0019 & 119.70 & 0.0008 & 49.87 & 129.32 & 0.0021 & 73.31 \\
6.4677 & 0.0024 & 119.70 & 0.0010 & 49.87 & 131.23 & 0.0024 & 78.18 \\
7.5526 & 0.0038 & 119.70 & 0.0017 & 49.87 & 133.10 & 0.0035 & 82.99 \\
8.6272 & 0.0080 & 119.70 & 0.0010 & 49.88 & 134.94 & 0.0096 & 87.71 \\
\hline
\end{tabular}

the emf produced by the thermopile and the cold-junction temperature from the data set collected for the calibration experiment. The resistance values from the platinum 


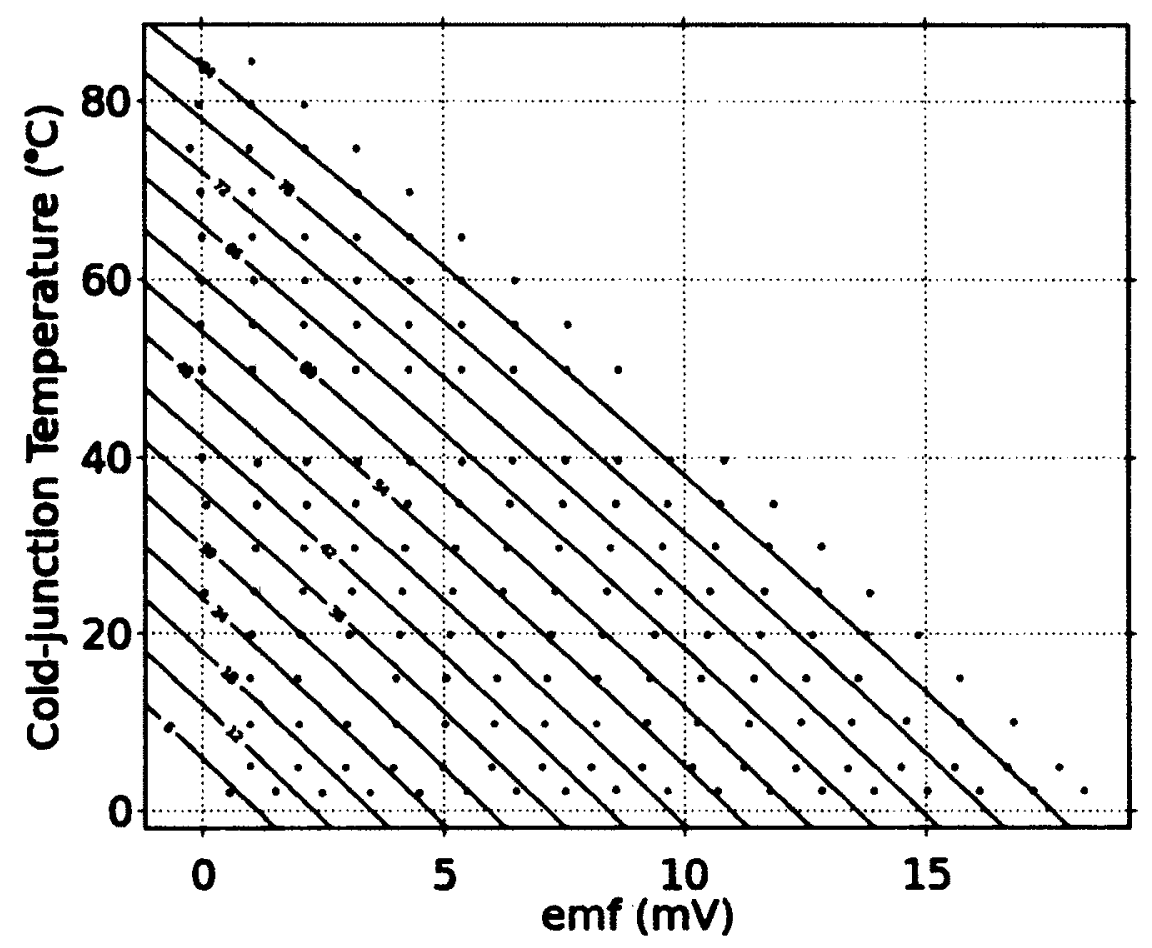

Figure C.1: Thermopile calibration data

thermometers were converted into ${ }^{\circ} \mathrm{C}$ using curve fits of the calibration data provided by the manufacturer. Equation C.1 was used to convert the resistance values from the cold temperature bath while Equation C. 2 was used for the hot bath temperatures.

$$
\begin{aligned}
& T\left({ }^{\circ} \mathrm{C}\right)=0.001 R^{2}+2.309 R-240.843 \\
& T\left({ }^{\circ} \dot{C}\right)=0.001 R^{2}+2.300 R-240.863
\end{aligned}
$$

Multivariate regression was used to express the hot-junction temperatures as a function of cold-junction temperature and emf produced. A 10-coefficient cubic was ultimately chosen as it provided the best representation of the data. The polynomial resulting from the calibration experiment is shown below and the coefficints are listed 
in Table C.2 The coefficients were weighted such that the maximum value of the absolute error between the measured values and the ones predicted using the curve fit was minimized.

$T_{H J}=a+b e m f+c T_{C J}+d e m f^{2}+f T_{C J}^{2}+g e m f^{3}+h T_{C J}^{3}+i e m f T_{C J}+j e m f^{2} T_{C J}+k e m f T_{C J}^{2}$

Table C.2: Thermopile regression coefficients

\begin{tabular}{cc}
\hline Coefficient & Value \\
\hline \hline a & $-6.9185613467257445 \mathrm{E}-01$ \\
b & $5.1683542486939711 \mathrm{E}+00$ \\
c & $9.8133216067597717 \mathrm{E}-01$ \\
d & $2.7883637404332424 \mathrm{E}-02$ \\
f & $2.2893880402369271 \mathrm{E}-04$ \\
g & $2.3694605271328006 \mathrm{E}-04$ \\
h & $-6.7512031136812368 \mathrm{E}-07$ \\
i & $-1.1230683426105850 \mathrm{E}-02$ \\
j & $1.7460387464790389 \mathrm{E}-04$ \\
k & $2.2951552440429009 \mathrm{E}-05$ \\
\hline
\end{tabular}

The maximum error introduced by the regression equation was calculated to be $0.087^{\circ} \mathrm{C}$ which accounts for the largest source of error associated with temperature measurement using the thermopiles. Figure C.2 shows the distribution of the regression prediction error resulting from the curve fit. 


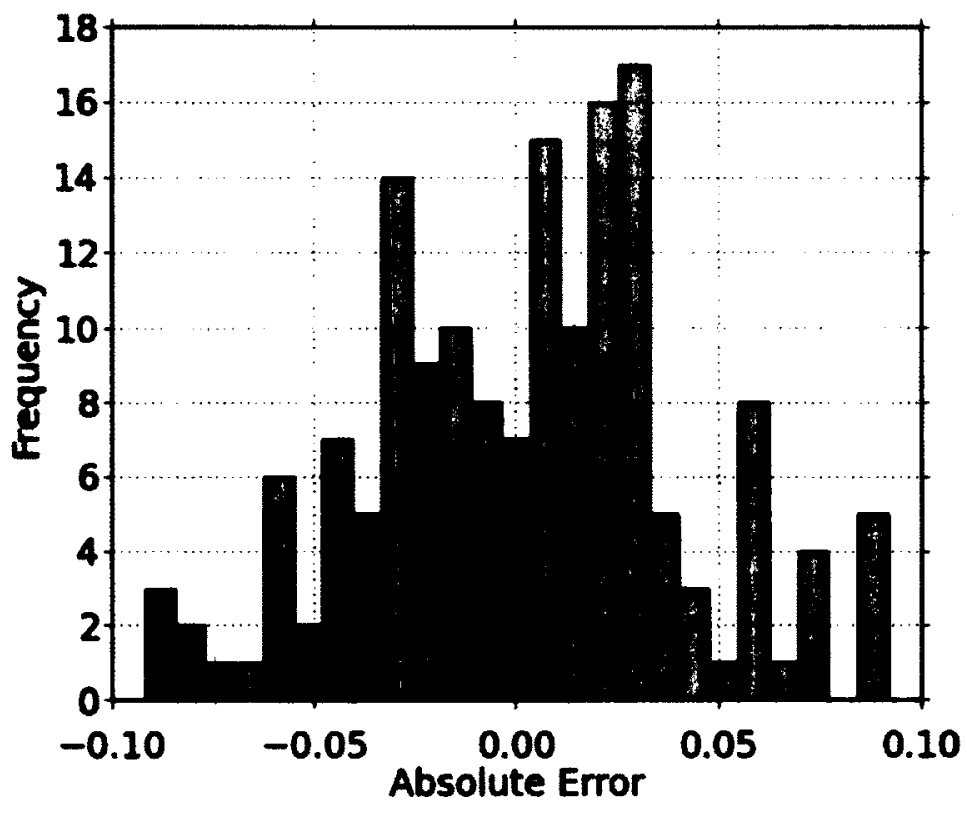

Figure C.2: Thermopile regression errors 
Appendix D

Natural Gas Sampling 